\title{
Evaluating Post-Fire Vegetation Recovery in North American Mixed Prairie Using Remote Sensing Approaches
}

\author{
Meng Li, Xulin Guo* \\ Department of Geography and Planning, University of Saskatchewan, Saskatoon, Canada \\ Email: *xulin.guo@usask.ca
}

How to cite this paper: Li, M. and Guo, X.L. (2018) Evaluating Post-Fire Vegetation Recovery in North American Mixed Prairie Using Remote Sensing Approaches. Open Journal of Ecology, 8, 646-680. https://doi.org/10.4236/oje.2018.812038

Received: November 6, 2018

Accepted: December 18, 2018

Published: December 21, 2018

Copyright $\odot 2018$ by authors and Scientific Research Publishing Inc. This work is licensed under the Creative Commons Attribution International License (CC BY 4.0).

http://creativecommons.org/licenses/by/4.0/

\begin{abstract}
Research on the effects of fire on grassland ecosystems yields among the most controversial research results. This is caused by the global distribution of grasslands under different environmental conditions in addition to complex fire characteristics (time, severity, frequency, history etc.). Challenges and discrepancies arise from various temporal and spatial scales, as well as methods used. Moreover, the function of fire can be different from one grassland to another. In the large body of grassland fire literature, the Canadian northern mixed prairie is understudied, especially regarding the vegetation's post-fire recovery. The wildfire in April 2013 provided an opportunity to study how the grassland responded to the burning, and particularly how remote sensing can provide potential solutions to grassland fire studies in this region. This research investigated the vegetation's post-fire recovery using six years' field survey data. Results indicate a quick overall recovery of the grassland, but with different vegetation forms recovering at various post-fire growing seasons. Green grass was the most resilient component that fully recovered one year post-fire, followed by forbs at two years post-fire, with shrubs and the soil organic crust taking longer than four years to recover. The ecosystem recovered to the unburned state roughly after four years. This conclusion agrees with the shortest fire interval of some research, probably because of the heavy fuel loading before the wildfire, due to Grasslands National Park's long-term conservation practice. Both hyperspectral data and historical Landsat images were investigated to demonstrate their effective assessment of the post-fire grassland vegetation recovery trajectory.
\end{abstract}

\section{Keywords}

Grassland, Fire, Vegetation Recovery, Trajectory, Landsat 


\section{Introduction}

Various biotic and abiotic factors can modify the composition and structure of grasslands [1]. Of all those factors, the impact of fire is the most controversial due to its complex nature. There exists a large body of literature studying fire's effect on grassland ecosystems considering fire severity, fire frequency, and fire season (for example, [1] [2] [3] [4]). Though general conclusions can be reached regarding fire's impact, there are conflicting results within literature possibly due to different localities of grasslands ecosystems as well as limited resources available to most existing investigations.

Fire has been a significant ecological process on this planet for a very long time, and its impact on terrestrial ecosystems is well documented [2]. Some examples of its impact being: 1) the shaping of the global biome distribution, 2) maintaining the structure and function of fire-prone communities, 3) acting as an evolutionary force, 4) being employed as one of the first tools by humans to re-shape the world. Fire has a significant impact on flora and fauna in the grassland ecosystem, in both direct and indirect ways. Direct effects include mortality of individuals, which are short-term. Indirect effects, such as species composition and changes in habitat, are long-term. Indirect impacts are not as easy to observe and evaluate but are usually more important than short-term effects given the scale of the impact on the ecosystem. Fire, coupling with other numerous factors, i.e. topography, soil, fauna (insects, herbivores), together with herbaceous plants [3] [4], can restrict the encroachment of woody plants (trees, shrubs) and release nutrients bound up in organic matter, accelerating the rate of decomposition in the soil, so as to maintain the establishment and the stability of grasslands [4] [5] [6]. Descriptive studies [7] [8] show that fire occurrences decrease herbaceous production for one to three years. Meanwhile, the herbaceous response is influenced strongly by precipitation. Fire also reduces woody plant cover and promotes herbaceous dicotyledons. Plant species in semi-arid grasslands are more likely to be subject to fire season and frequency rather than fire behaviour [9].

The reestablishment of periodic fires is fundamental to the ecological restoration of grasslands on the Great Plains [5]. The significance of the reestablishment of fire regimes has been recognized as fundamental to the ecological restoration of grasslands [5]. However, current understanding of fire's effect on the grassland ecosystem still needs to be improved. Based on historical materials about the Canadian prairies, Rannie [10] reviewed the history of wildfires and identified a "grass fire era" from the late $18^{\text {th }}$ century to the late $19^{\text {th }}$ century with much enhanced anthropogenic grassland fires. Moreover, Wakimoto et al. [11] did similar work but with more effort in determining and reconstructing historical fire regimes and fire behaviours in the northern mixed-prairie through reviewing and summarizing available resources such as 1) diaries and reports of travellers, 2) photographic records, 3) oral histories of First Nations, 4) related research literature. According to their investigation, evidence of past fire regimes 
mostly relies on historical accounts of early travellers. However, these written and oral accounts vary in detail and quality, and records are quite limited. General conclusions about historical fire frequency can also be reached based on rates of fuel accumulation and woody plant invasion [12], as well as charcoal remains from lake sediment cores [13]. In regions of grasslands with trees, tree fire scars can also be used to study historical fire regime. Furthermore, tree-ring studies help establish drought cycles and their duration, which in turn provide information about historical climate, fuel loading, and potential fires. However, this remains a challenge if woody plants are scarce; because grasses and forbs do not carry fire scars and growth ring patterns [11].

There are two major fire types: wildfire and prescribed fire. Wildfires provide first-hand data for grasslands fire studies, such as [14]. By compiling the wildfires which occurred in the region (most of them in late summer), Kruger [15] investigated fire's immediate and long-term effect on forage species as well as other range plant species on the northern mixed prairie. A typical methodology can be found in [11] [15]. By surveying the vegetation and soil properties at burned sites and its adjacent unburned sites, the hypothesis of no differences across sites can be tested with statistical analysis (e.g. t-test). Fire's long-term impact can also be analyzed with field surveys of longer periods or intervals, e.g. $<5$ years, $>5$ years, 10 years, 15 years [11] [15]. However, such wildfire studies have obvious limitations. Besides expensive sampling effort, no systemic evaluation of fire regime can be conducted, and it is impossible to know when and where wildfires will occur [11]. A large body of literature is dedicated to controlled burning, or prescribed fires, including academic as well as applied researches on various types of grasslands on the Great Plains (e.g. [5] [16]-[22]). Moreover, detailed long-term ecological researches have been designed and implemented, such as the famous Long-Term Ecological Research program (or LTER, more details available from [23] [24] [25]), to understand the fundamental mechanisms of fire's effect on grasslands ecosystems. A good review of the ecological effects of prescribed fires can be obtained from [19] with their central region covering the northern mixed-prairie. Prescribed fires are effective in identifying the basic principles of fire through extrapolation, synthetization and generalization [22]. Based on the established understanding of ecological processes and mechanisms, ecological models can be developed to simulate vegetation dynamics and quantify various fire regimes, such as the LANDFIRE model from the US Department of Agriculture [26] to study fire regimes of different ecosystems including part of the mixed prairie. Though prescribed fire experiments and fire modelling have significantly improved our understanding of fire's impact, both are resource-consuming and not readily portable to different locales.

Various approaches have been provided to evaluate fire effects in grassland. The USDA conducted a comprehensive review [19] on the ecological effects of fire, aiming to provide well-rounded information for range managers to effec- 
tively use prescribed fire as a management tool. Part of their investigation covers the Canadian prairie in GNP. In general, they found that post-fire response of organisms depends on the complex interactions between a myriad of factors, including time of prescribed burning, historical fire regime, phenological stage of the organisms, fire severity of different burn seasons, climatic variation within or across burn seasons. Research from the Great Plains (such as [12]) indicates that fire generally decreases shrub coverage and increases the cover of graminoid species as well as the percentage of live vegetation. In contrast, lack of fires from active suppression causes direct woody species encroachment, such as big sagebrush, ponderosa pine and Douglas fir [11]. Ford and Johnson [5] reported that in general, grass cover recovered quickly from the fire treatment, and the long-term effect of fire was neutral. Burning during the dormant-season had little effect on grass cover when the burning site was revisited and sampled after as little as two months from the time of the prescribed fire. Meanwhile, burning during the growing season seems to negatively impact grass cover for up to two years after the fire. Studies [16] [27] [28] on the effects of the seasonality of fire (spring fire) on buffalograss and blue grama indicated mixed results, over a time frame of three months to 16 years. Often, early-spring burns (March) produce neutral or positive responses; and late-spring burns (May) produce negative results. Whereas fall burns led to more yield than did spring burns. Negative, neutral and positive responses to fire were evident in both season-long grazed areas [16], and areas protected from domestic livestock grazing [7]. Shortgrass prairie ecosystem recovers relatively quickly from fire disturbance. Vegetation cover, arthropod, and mammal species abundance treated with dormant-season fire recovered in approximately two months and showed no significant difference from untreated communities. By studying vegetation response (grass cover) to different timings of fires (dormant season versus growing season), Ford and Johnson [5] concluded that in the short-term, burning during the growing-season appears to reduce fire severity but exerts greater impact on grass communities (opposite for soil crusts) compared to burning during the dormant season. Dormant-season fire in the shortgrass steppe is less damaging to grass communities (opposite for soil crusts) than growing-season fire. Wakimoto et al. [11] used vegetation similarity values to quantitatively measure the similarity between vegetation cover types between burned and unburned sites. For grassland and shrub-land, vegetation similarity values are consistently and significantly different across treatments, indicating the fact that burned communities cannot return to the unburned status even after 10 years' plant succession. Grassland sites however, do not show a significant difference either short-term or long-term, i.e. 1 - 2, 3- 5, 6-10, >10 years. Wakimoto et al. [11] also found that fire affected the vegetation structure of $62 \%$ of surveyed sites. Such structure change tended to happen on sites with shrubs. Shrubs are more susceptible to fire mortality, with some shrub species being especially sensitive to fire. They found that shrubs were killed entirely at some shrubland sites, converting the 
vegetation cover from pine-shrubland-grass to wheatgrass-needlegrass. No such change occurred at wheatgrass-grama-needlegrass sites.

Fire showed different effects on various major grassland species. Kruger [15] found that burned sites showed more cover of blue grama, sandberg bluegrass and green needlegrass one year post-fire. Such an increase became less obvious 2 - 5 years post-fire. After 6 - 15 years post-fire, these species showed mixed results; with some slightly higher and some slightly lower. Meanwhile, unburned grassland and shrubland had more undesirable species compared with burned sites. After 15 years post-fire, burned and unburned sites showed little difference when compared with each other. Comprehensive and detailed species' response to fire can be accessed at [11] as well as the USDA's Fire Effects Information System [29].

Obviously, as an important ecological factor, fire has been studied extensively in tallgrass, shortgrass as well as mix-grass prairie in the central and southern parts of the North American Great Plains [4] [6] [17] [19]. For different grasslands, the influence of fire may contribute to different vegetation responses. For example, Oesterheld et al. [30] showed contrasting productivity responses for subhumid versus semiarid grasslands. Most research on grassland fires deals with particular local landscapes and ecosystems. We must be cautious when interpreting the results from different researchers on the impact of fire on the grassland ecosystem, because Ford and Johnson [5] confirmed that impact of fire varies for different types of plants according to their active growth season, with C4 plants least vulnerable to the dormant-season fire and most vulnerable to the growing season fire. And research findings from different localities can vary significantly due to differences in historical and current prescribed fire regimes [19]. Guo et al. [31] found that aboveground dry biomass, plant moisture, and dominant species together with plant forms are different for cool seasons and warm seasons on tallgrass prairie. With unique flora and fauna composition, the Canadian northern mixed prairie can be significantly different from other grasslands. However, little is known about fire effects on the semiarid mixed-grass prairie in Canada [32]. There is a lack of knowledge about the pre-settlement fire regime [33] and under-standing of fire effects on the dynamics of that ecosystem, especially the plant communities [34] [35].

All previous research on vegetation responses to fire in this region are based on the short-term investigation (less than a year, see [35] [36]). However, grassland communities have evolutionary adaptations, showing variation in population recovery dynamics from fire season, frequency and behaviour [33]. As a result, fire regime should be studied in more consistently and reliably, at longer terms and finer temporal resolutions. Long-term field studies with climate disturbances suggested that short-term ecosystem responses are usually opposite to long-term responses [23]. Vegetation recovery is critically important because it plays a significant role in maintaining the grassland ecosystem through its influence in runoff, soil moisture, spatial distribution of erosion-deposition, nu- 
trients as well as other biophysical activities [37].

Quantifying long-term grassland recovery trajectory after fire is important for ecosystem sustainability. Remote sensing provides new ways to conduct grassland fire studies. The contribution of remote sensing in fire studies has been recognized since the 1970s [38] for forest fire monitoring and control efforts. Performance of various satellite sensors have been tested in fire studies including ERS-1, GOES, DMSP, AVHRR, Landsat (a review can be retrieved at [39], SPOT [35], and MODIS [40]). LTER investigated the sensitivity of the Landsat product to distinguish burned from unburned grasslands with positive results [23]. Remote sensing based approaches have obvious advantages compared to conventional field surveys by providing timely and cost-effective imagery at various scales. Related studies have confirmed the robust performance in the sensitivity of remote sensing data in capturing the spectral characteristics of wildfires to study their occurrence, size and severity [35] [41] [42]. Besides visible bands (sensitive to blackened, charred vegetation), other bands are also proved effective, including NIR [23] (sensitive to green vegetation) and SWIR bands (sensitive to moisture content) [35] [42]. Furthermore, various vegetation indices and specifically burn indices have been designed for fire studies [35] [36] [40]. Time series of burn patches can be mapped with remote sensing approaches [43]. Also Yang et al. [35] and Lu et al. [36] have demonstrated the feasibility of using remote sensing in evaluating grassland fires in the northern mixed prairie. However, a comprehensive examination of fire effects on the ecosystem is needed to further our understanding about ecosystem dynamics, especially vegetation responses to fire. This research intends to investigate the vegetation recovery trajectory of the C3 dominated northern mixed grassland from a spring fire event, focusing on a longer historical perspective with remote sensing approaches. Field data were collected before the burn and five growing seasons following the burn. Various spectrum bands, vegetation and fire indices developed for the Landsat product are tested for their capacity in distinguishing burned and unburned areas as well as studying the long-term vegetation recovery trajectory.

By investigating a wildfire that took place on April 27 $7^{\text {th }}, 2013$ with the help of a time series of remote sensing data, this study tries to understand fire's immediate and long-term effects on the northern mixed-prairie. Specifically, there are two major research objectives:

- To evaluate fire's effect on the northern mixed-prairie using field survey data;

- To investigate the application of remote sensing approaches in grasslands post-fire recovery study.

o to verify the feasibility of remote sensing in the fire study using the hyperspectral measurement from the field survey;

0 to test the performance of satellite remote sensing products together with the ground surveyed data derived from Objective 1;

o to identify the grassland post-fire recovery trajectory with the most suitable remote sensing satellite products. 


\section{Materials and Methods}

\subsection{Study Area}

The study area is located in the west block of Grasslands National Park (GNP), on the border of Saskatchewan (CA) and Montana (US) (Figure 1). It is situated in the prairie ecozone and has been providing habitats for a rich diversity of flora and fauna that have evolved in a highly dynamic environment which includes grazing, prairie wildfires, soil erosion, drought, and flooding [44].

Grasslands are characterized by rapid growth and slow decomposition rates due to the chemical and physical composition of the plants [22]. The decomposition of aboveground materials by microorganisms is limited in grassland and can be accelerated post-fire due to a higher temperature and more available nutrients [22]. Fire plays a significant role in the mixed prairie. This makes fire the primary decomposition agent and important nutrient cycler of the grasslands ecosystem [22]. A survey [14] indicated that naturally caused fires (lightning) are relatively common in the grassland here, with one year in six years having abundant fuel and suitable weather conditions to encourage fire occurrence. Through evolutionary history, grasslands ecosystems were maintained in conditions appropriate for their productivity and biodiversity in nature, by self-organizing all the biotic and abiotic components into equilibrium [18]. However, most disturbances were removed since the human settlement in the 19th century. Wildfire was actively suppressed, resulting in near-total fire extinction and major shifts in ecosystem structure and function, with $80 \%$ of the native prairie lost forever [45]. In light of this, GNP was founded in 1988 with its mission to preserve the still standing pristine mixed-grass prairie in North America [45] [46].

The area is semi-arid, with annual precipitation between 300 and $330 \mathrm{~mm}$, and average temperature ranging from $28^{\circ} \mathrm{C}$ in the summer to $-22^{\circ} \mathrm{C}$ in the winter. The dry air, strong sunshine and high winds result in evaporation up two times the moisture gained from precipitation, encouraging wildfire occurrence [45]. Poorly distributed precipitation patterns and frequent drought are typical in the mixed-prairie. Wind prevails in all seasons, with velocities exceeding most other parts of the continent. Arctic air mass forms northerly winds that drive blizzards across this region in winter, whereas in summer winds are hot and dry, resulting in parched and dusty prairie [15]. The dominant landscape of the west block in GNP is rolling uplands and river valley, with elevation varying from $770 \mathrm{~m}$ to $900 \mathrm{~m}$ above sea level. The nearly level to slightly rolling topography encourages dry winds to carry wildfires and spread it quickly, with few obstacles to slow down or stop the fire's progress [22] [47]. The park is dominated by grasses (family of Poaceae) and non-graminoid herbaceous plant called forbs, with few trees and some shrubs along the river valley (Figure 1). Both cool season species and warm season species are found on this prairie, with the former showing dominance [48]. Cool season grasses start growing in the spring as soon as the temperature rises. They become mature and then are dormant in the summer 


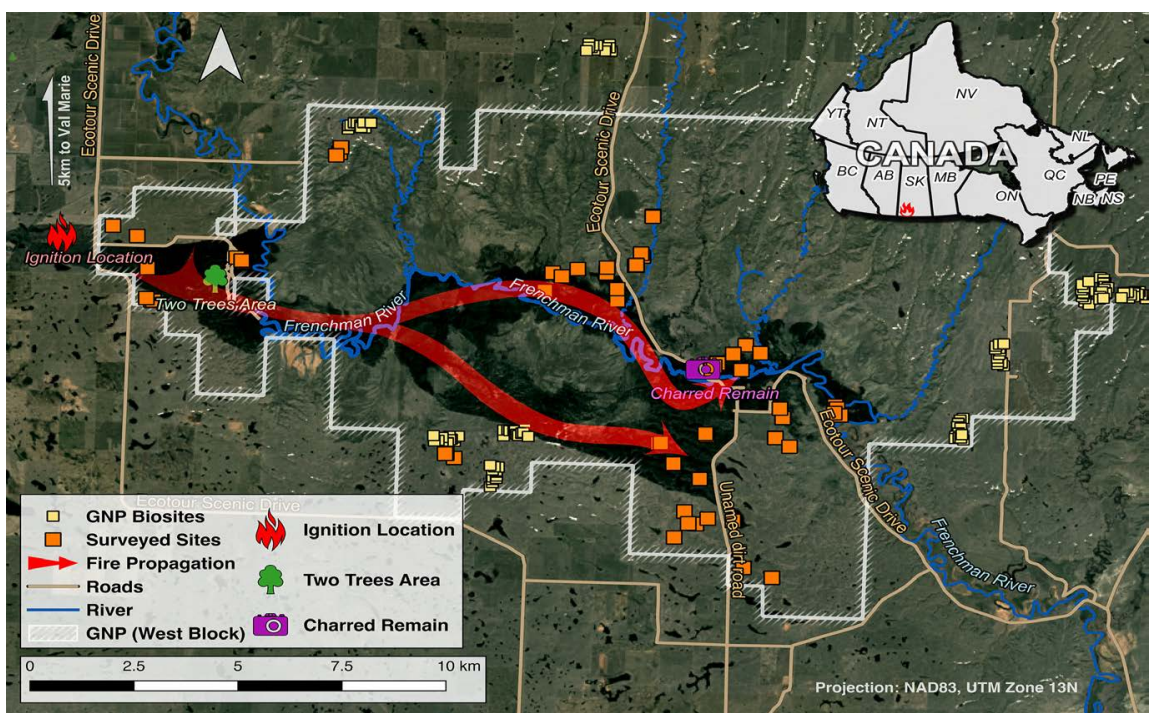

Figure 1. The study area is located at the West Block of Grasslands National Park, Canada. Background of this image is a natural colour composite of Landsat 8 imagery (May ${ }^{\text {st }}$ ), acquired three days after the fire's occurrence on April 27 $7^{\text {th }}, 2013$. The fire started close to the park's west border (marked as "Ignition Location") and quickly spread eastward across the park, burning approximately $1 / 3$ of the west block. Burn severity varies, as indicated by different intensities of the black colour (charred material). Notice the isolated unburned grassland "pockets", of which the most prominent one is formed by the fire's two heads (one along the Frenchman River Valley, the other to the south).

due to lack of appropriate moisture. Warm season grasses start growth in early summer and the length of their growing season depends on the availability of moisture. The dominant grass species include needle-and-thread grass (Stipa comata), western wheatgrass (Agropyron smithii) and blue gramma (Bouteloua gracilis) [49].

\subsection{The Wildfire and Its Propagation}

On April 27 ${ }^{\text {th }}, 2013$, a wildfire spread into GNP from adjacent agricultural lands. The fire consumed 4500 hectares (11,500 acres) and extended over $16 \mathrm{~km}$ (10 miles) (Figure 1) in less than four hours, due to high winds and low humidity [50]. In the following two months (May and June), above normal precipitation $(\sim 230 \mathrm{~mm}$, Weather Canada Historical Climate Data) resulted in rapid vegetation recovery. This wildfire provided an outstanding opportunity to examine the impact of a large-scale fire on the preserved grassland and how the ecosystem recovers over time.

This wildfire occurred when the park was still undergoing the spring green up (initiation of spring growth). Therefore, there existed a considerable amount of litter content, including standing dead (or senesced vegetation from the previous growing season) and litter (fallen or partially decomposed vegetation); both contributed as fuel load to feed the wildfire. Furthermore, the conservation effort led to the buildup of the dead material (similar as in other grasslands, e.g. [51]), or rather, excessive fuel loading, for more than 20 years, making the park accu- 
mulate a considerably greater amount of litter content than the surrounding farmlands [52]. The weather at the time of fire's occurrence further encouraged its fast spread. Weather record shows that during the fire's occurrence relative humidity averaged at $23 \%$ with a strong westerly wind blowing at $40 \mathrm{~km} / \mathrm{h}$. The forward rate of spread under such high wind would be over 100 times the zero wind spread rate [53]. Once the fire spread for $1 \mathrm{~km}$ eastward and crossed the park's boundary, its consuming rate accelerated due to the abundant fuel load within the park as well as the alignment between the wind direction and the east-west direction of the Frenchman River valley. As a result, the fire quickly started to propagate within the park. The burned patch is clearly visible (Figure 1) on Landsat 8 OLI imagery from May $1^{\text {st. }}$.

Topography also played a significant role in shaping the fire's propagation path and its burning intensity. Figure 2 shows that after the fire crossed the park's boundary, it kept travelling eastward in a narrow path along the Frenchman River valley for about five kilometres. Then it split into two fire fronts and continued spreading as a north head and a southern head. The northern head kept consuming the dry fuel along the valley. In contrast, the southern head took a southwest turn and travelling in an almost straight line, a commonly observed feature for flanking fires under high wind influence [53]. When the southern head was stopped by the unnamed dirt road (Figure 2), it travelled northward merging into the fire's northern head. Then the fire continued spreading for another three kilometres along the river valley and finally stopped close to the park's boundary on the other side.

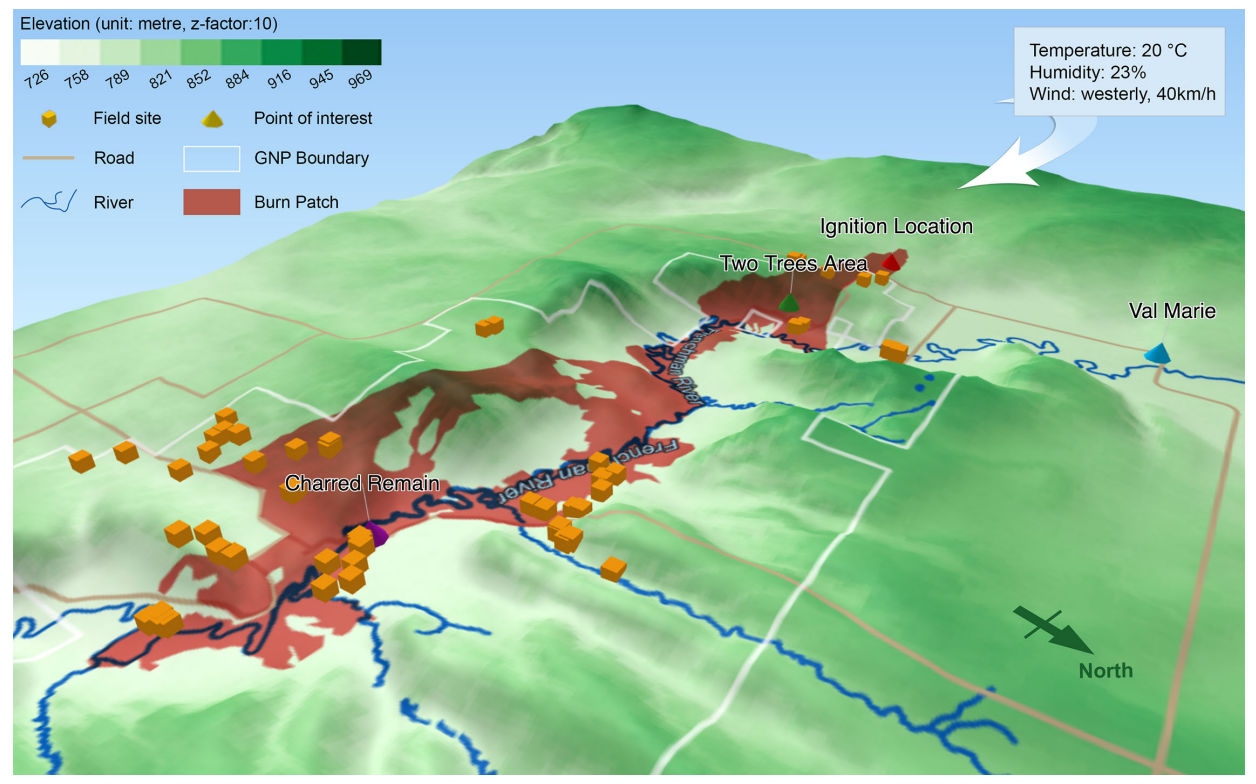

Figure 2. Ignition, spread and intensity of the wildfire under the influence of weather and topography. The $3 \mathrm{D}$ visualization of the terrain illustrates the fire's propagation. Weather data were acquired from Environment Canada on the day of the fire's occurrence. DEM data was from NASA SRTM Global v3 in 2012. Burn patch was digitized from Landsat 8 OLI image on May $1^{\text {st }}, 2013$. 


\subsection{Data Collection}

\subsubsection{Field Data}

Field data were collected in the study area for six years (the year before the fire-2012 and five years after the fire-2013-2017). Each year about 10 sites were selected with a stratified random method for both burned and unburned areas. Each site was $100 \mathrm{~m}$ by $100 \mathrm{~m}$ in size [54], to effectively capture the minimum spatial variation in products from moderate resolution satellites (e.g. Landsat). Field sites were selected with at least $130 \mathrm{~m}$ apart from each other (Figure 1) to avoid autocorrelation [35] [55]. Each site contains 20 quadrats distributed as four wings (north, south, west, east) with five quadrats for each wing.

Field measurements were taken at each quadrat and later averaged into a single value at the site level in this study. Primary datasets included biophysical parameters (grass life form composition, dominant species, biomass, canopy height, LAI, and ground reflectance) and soil parameters (temperature, moisture and electric conductivity). Using a $50 \mathrm{~cm}$ by $50 \mathrm{~cm}$ square quadrat, vegetation's life form composition was determined as ground cover percentages of different components: green grass (graminoid species), standing dead, litter, forb, moss, lichen, shrub and bare soil. For key biophysical parameters, measurements were estimated visually by the same recorder in the field season to ensure consistency and reliability of the dataset. Photos of vegetation structure were also taken for later reassessment if required. LAI was measured using the LI-COR LAI-2000 Plant Canopy Analyzer. Soil data were collected using Decagon Pro-Check Sensor Readout and Storage System. Close range hyperspectral data were collected in the field survey using a portable spectroradiometer (Analytical Spectral Device, or ASD).

This research compiled all available biophysical parameters and used plant form information as the major indicator of post-fire recovery though other parameters were also included. Plant form information was estimated in the field with a $50 \mathrm{~cm}$ by $50 \mathrm{~cm}$ quadrat consistently in six years following the same protocol. These derived parameters were calculated from the biophysical parameters measured in the field: 1) cover of live component was the sum of green grass, forb and shrub cover; 2) cover of dead component was the sum of the standing dead and litter; 3) ratio of green and dead component; 4) standardized difference of green and dead component. The latter two parameters were designed to factor in both live and dead components and served as a comprehensive indicator of post-fire recovery.

\subsubsection{Satellite Imagery}

Landsat 7 and 8 products were used in this study. Atmospheric correction was performed when needed. Landsat scenes were downloaded in GeoTIFF format from USGS's EarthExplorer data portal.

To check the performance of the satellite remote sensing product, each year's field survey data was paired with a scene with the closest acquisition date. When 
the imagery's quality was severely impacted by clouds, scenes of adjacent paths or dates were used instead (Table 1).

To match the footprint of field site at $100 \mathrm{~m}$ by $100 \mathrm{~m}$, centers of field sites were buffered with $100 \mathrm{~m}$ and zonal statistics was used in ArcGIS 10.5 for calculating the average reflectance values of Landsat bands at the field sites. The reflectance data were used to compute vegetation indices shown in Table 2.

Table 1. Acquisition Date of Landsat scenes used in this study. Dates in italics were paired with the field survey of the same year.

\begin{tabular}{ll}
\hline Product & Acquisition Date \\
\hline Landsat 7 & 2012 June $30^{\text {th }}$ \\
\hline & 2013 May $1^{\text {st }}$, June $2^{\text {nd }}$, June $18^{\text {th }}$, July $4^{\text {th }}$, Aug $5^{\text {th }}$, Sept $6^{\text {th }}$, Oct $8^{\text {th }}$ \\
& 2014 May $11^{\text {th }}$, June $12^{\text {th }}$, July $14^{\text {th }}$, Aug $8^{\text {th }}$, Sept $16^{\text {th }}$, Oct $11^{\text {th }}$ \\
& 2015 Apr $28^{\text {th }}$, June $8^{\text {th }}$, July $10^{\text {th }}$, Aug $11^{\text {th }}$, Sept $12^{\text {th }}$, Oct $14^{\text {th }}$ \\
Landsat 8 & 2016 Apr $7^{\text {th }}$, Apr 23 rd, June $10^{\text {th }}$, June $17^{\text {th }}$, July 3 rd, July $19^{\text {th }}$, July $28^{\text {th }}$, Aug $4^{\text {th }}$, Aug $13^{\text {th }}$, \\
& Aug $29^{\text {th }}$, Sept $14^{\text {th }}$, Sept $30^{\text {th }}$ \\
& 2017 Apr $10^{\text {th }}$, May $3^{\text {rd }}$, May $19^{\text {th }}$, May $28^{\text {th }}$, June $4^{\text {th }}$, June $20^{\text {th }}$, July $6^{\text {th }}$
\end{tabular}

Table 2. Spectral indices widely used in burn severity analysis included in the study.

\begin{tabular}{|c|c|c|}
\hline Spectral Index & Abbr. & Formula \\
\hline $\begin{array}{l}\text { Normalized Difference } \\
\text { Vegetation Index }\end{array}$ & NDVI & $\mathrm{NDVI}=\frac{N I R-R e d}{N I R+R e d}$ \\
\hline $\begin{array}{l}\text { Global Environmental } \\
\text { Monitoring Index }\end{array}$ & GEMI & $\begin{array}{l}\text { GEMI }=\Upsilon(1-0.25 \Upsilon)-\frac{\operatorname{Red}-0.125}{1-\operatorname{Red}} \\
\Upsilon=\frac{2\left(N I R^{2}-\operatorname{Red}^{2}\right)+1.5 N I R+0.5 \operatorname{Red}}{N I R+\operatorname{Red}+0.5}\end{array}$ \\
\hline $\begin{array}{l}\text { Enhanced Vegetation } \\
\text { Index }\end{array}$ & EVI & $\mathrm{EVI}=2.5 \frac{N I R-\text { Red }}{\text { NIR }-6 \text { Red }-7.5 \text { Blue }+1}$ \\
\hline $\begin{array}{l}\text { Soil Adjusted Vegetation } \\
\text { Index }\end{array}$ & SAVI & $\begin{aligned} \text { SAVI }=(1+\mathrm{L}) & \frac{N I R-R e d}{N I R+R e d+L} \\
\mathrm{~L}= & 0.5\end{aligned}$ \\
\hline $\begin{array}{l}\text { Modified Soil Adjusted } \\
\text { Vegetation Index }\end{array}$ & MSAVI & MSAVI $=\frac{2 N I R+1-\sqrt{(2 N I R+1)^{2}-8(N I R-R)}}{2}$ \\
\hline Burned Area Index & BAI & $\mathrm{BAI}=\frac{1}{(0.1+R e d)^{2}+(0.06+N I R)}$ \\
\hline $\begin{array}{l}\text { Normalized } \\
\text { Burn Ratio }\end{array}$ & NBR & $\mathrm{NBR}=\frac{N I R-S W I R 2}{N I R+S W I R 2}$ \\
\hline Char Soil Index & CSI & $\mathrm{CSI}=\frac{N I R}{S W I R 2}$ \\
\hline $\begin{array}{l}\text { Mid Infrared } \\
\text { Burn Index }\end{array}$ & MIRBI & MIRBI $=10$ SWIR $2-9.8$ SWIR $1+2$ \\
\hline
\end{tabular}




\subsubsection{Meteorological Data}

Climate plays the most significant role in semi-arid mixed grasslands. Temperature, precipitation, and drought indicators were used to explain the post-fire recovery pattern. Temperature and precipitation records were acquired from a historical dataset authored by Environment Canada. Drought indicators include evapotranspiration, effective precipitation and moisture deficit. These drought-related datasets were based on Environment Canada's climate data [56] and acquired from FarmWest [57] at the monthly resolution. Figure 3 shows the compiled meteorological dataset used in this study.

\subsection{Data Processing and Analyses}

Methods used in this research can be described in Figure 4. Notice that symbols are colour coded per different purposes: gray for research data (both original and derived), orange for Objective 1, light blue for Objective 2.1, light green for Objective 2.2, and dark green for Objective 2.3.

Most analyses carried out in this research (Figure 4) were powered by open source solutions. Examples of software and packages include QGIS, Inkscape, R, Python and related scientific libraries. Examples of open data formats include CSV and GeoTIFF.

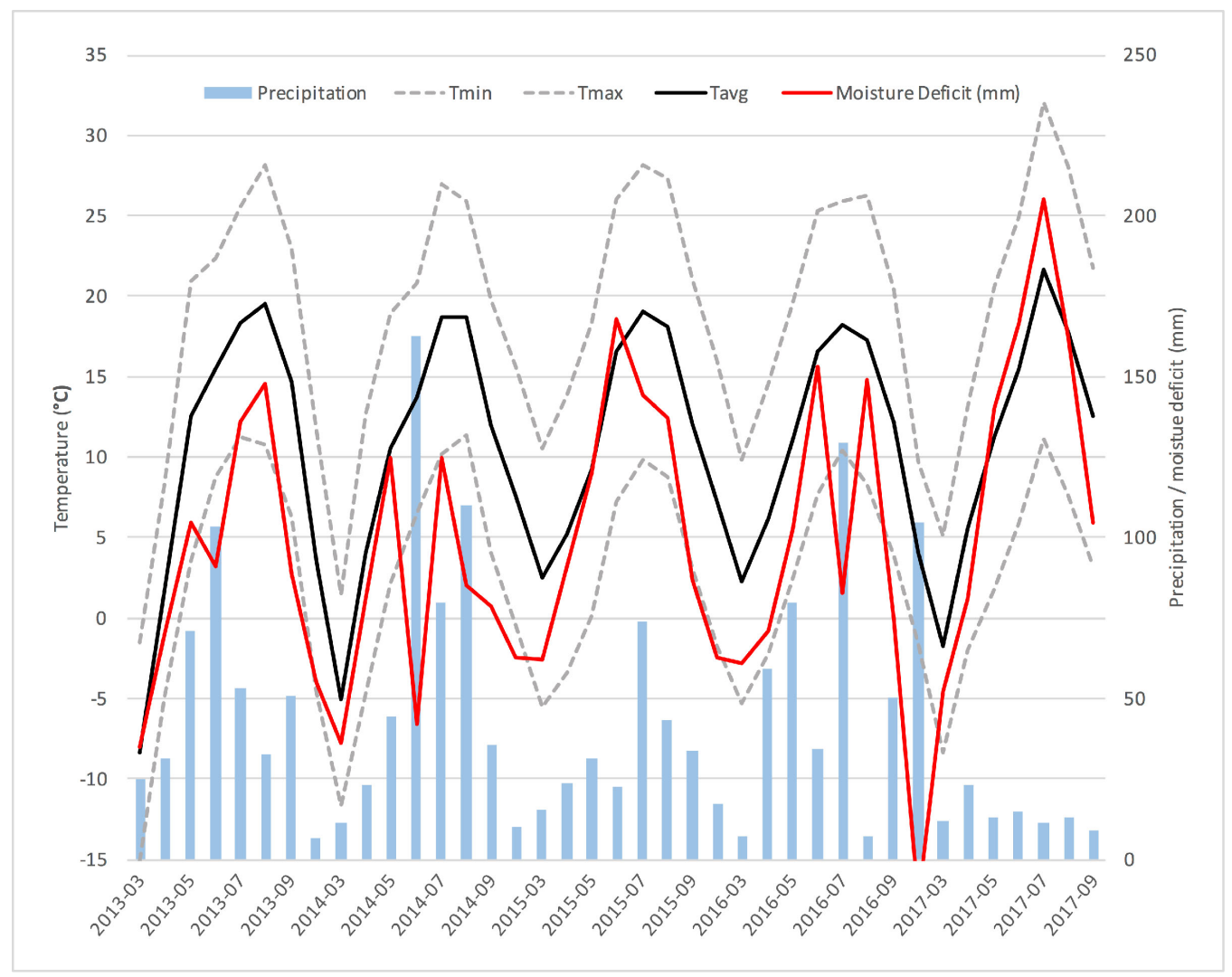

Figure 3. Monthly meteorological variables from 2013 to 2017. The X-axis displays months of the year. The primary $\mathrm{Y}$-axis shows temperature for maximum temperature (Tmax), minimum temperature (Tmin) and mean temperature (Tavg). The secondary Y-axis indicates precipitation and moisture deficit. 


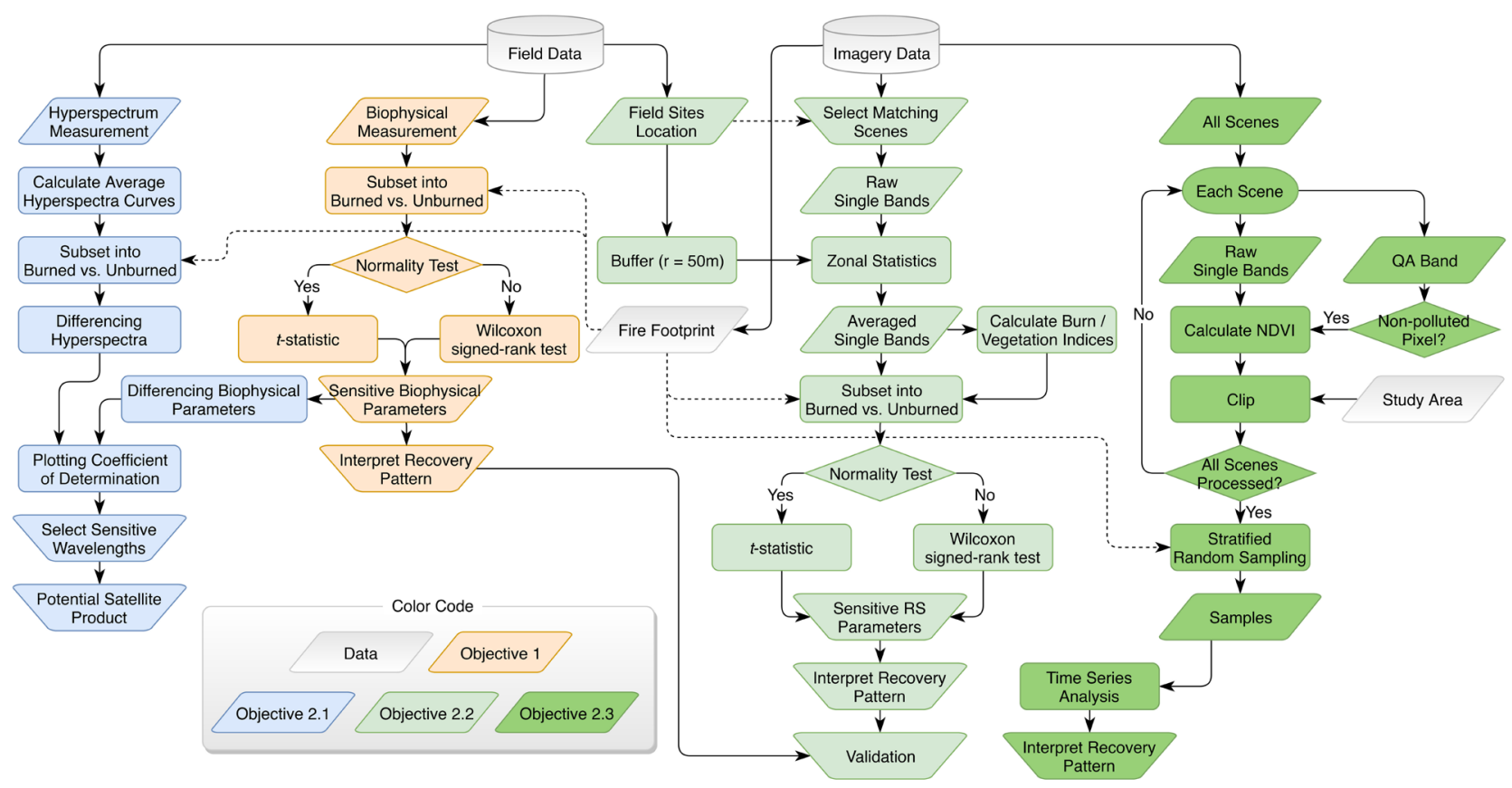

Figure 4. Overview of methods used in this research. This flowchart is colour-coded according to different objectives. Specifically, grey for research data (both original and derived), orange for Objective 1 (to study grasslands post-fire recovery pattern using field data), blue for Objective 2.1 (to verify the feasibility of remote sensing in the fire study by using hyperspectral measurement from the field survey), light green for Objective 2.2 (to test the performance of satellite remote sensing products linking with ground references derived from Objective 1), and dark green for Objective 2.3 (to reveal the vegetation recovery trajectory after fire using historical Landsat imagery).

Field samples (biophysical parameters) from 2012 to 2017 were collated and pre-processed (data cleaning and reformatting). Fire's footprint information was extracted from Landsat imagery (acquired on May $1^{\text {st }}, 2013$, or four days after the fire) and assigned to field data. Each year's field data were in turn imported into the R environment for statistical analysis.

Two higher level biophysical parameters were created by aggregating from the original parameters measured in the field. Specifically, the live component is the sum of green grass cover, forb cover and shrub cover (notice moss and lichen were excluded from the aggregation); whereas the dead component accounts for standing dead cover and litter cover. Furthermore two comprehensive biophysical parameters were derived to factor in both live and dead components: the simple ratio index (or SRIbio), and normalized difference index (or $\mathrm{NDI}_{\text {bio }}$ ) defined as follows:

$$
\begin{gathered}
\mathrm{SRI}_{\text {bio }}=\frac{\text { live } \%}{\text { dead } \%} \\
\mathrm{NDI}_{\text {bio }}=\frac{\text { live } \%-\text { dead } \%}{\text { live } \%+\text { dead } \%}
\end{gathered}
$$

here the subscript "bio" is used to explicitly indicate the fact that these are burn indices built with biophysical parameters, instead of using satellite product like normal VIs in the remote sensing context. 
Multivariate analysis of variance was applied to the variables for both biophysical parameters and spectral variables to detect the difference between burned and unburned sites. Statistic results were also used to produce a ternary plot that could be used to further understand the post-fire recovery dynamics at a higher level. Specifically, percentage of live component, dead component and the rest were plotted to emphasize how the configuration of these major components changed across different post-fire growing seasons. Sensitive parameters were selected and provided as main indicators for interpreting grasslands fire recovery pattern.

Close range hyperspectral reflectance data offers a broad range of wavelengths (from $350 \mathrm{~nm}$ to $2400 \mathrm{~nm}$ ) that can help us find sensitive wavelengths suitable for monitoring vegetation's post-fire growth. Ground reflectance data of all samples were compiled and grouped into burned and unburned categories. Mean reflectance curves were computed within each category for all years. Simple linear regression was used to find wavelengths that are sensitive to certain post-fire recovery biophysical parameters. Cross-sample differences of biophysical parameters were regressed by the cross-sample differences of narrow-band reflectance values. Coefficient of determination $\left(\mathrm{r}^{2}\right)$ and $\mathrm{p}$-value were compiled and plotted for diagnostics. From this procedure, sensitive narrow bands were determined. These bands served as the guide for evaluating satellite remote sensing product, here Landsat 7 and 8 , in modelling post-fire recovery.

$$
\operatorname{lm}(\text { resp } \sim \exp )
$$

where

$$
\begin{aligned}
& r e s p=\left(\text { Bio }_{\text {year_, }, \text { burned }}-\operatorname{Mean}\left(\mathrm{Bio}_{\text {year_, }, \text { unburned }}\right)\right)-\left(\mathrm{Bio}_{2012, \text { burned }}-\operatorname{Mean}\left(\mathrm{Bio}_{2012, \text { unburned }}\right)\right) \\
& \operatorname{expl}=\left(\operatorname{Ref}_{\text {year } \mathrm{i}, \text { burned }}-\operatorname{Mean}\left(\operatorname{Ref}_{\text {year } \_ \text {, unburned }}\right)\right)-\left(\operatorname{Ref}_{2012, \text { burned }}-\operatorname{Mean}\left(\operatorname{Ref}_{2012 \text {,unburned }}\right)\right)
\end{aligned}
$$

Im is a linear regression model fit to the data. The regression analysis resulted in a series of plots, of which the plot of $r^{2}$ was used to determine what wavelengths (indicated as Ref) can better explain the variation of fire-sensitive biophysical parameters. Wavelengths with good performance serve as reference for selecting suitable remote sensing data products via their spectral response functions [58] [59].

Objective 2.2 is to test the performance of satellite remote sensing products (suggested from Objective 2.1) against the ground reference derived from Objective 1. First, from the satellite imagery database, images less effected by clouds and shadows were selected as candidates, which are further narrowed down to select those that are the closest to the corresponding field survey dates. Then, field data and satellite remote sensing data of the same year were linked together based on their geographical locations. Field site locations were buffered with 50 $\mathrm{m}$ (arm's length). Zonal Statistics was performed with the buffer as the zones on all individual bands of the matched remote sensing scene, resulting in averaged single band reflectance for each site. Through predefined formulae (Table 2), 
vegetation/burn indices were calculated from averaged single band reflectance values. The averaged single reflectance and derived vegetation indices were assembled together and analyzed similarly as in Objective 1. After the statistical analysis, results from this section were compared against ground truth established in Objective 1 to validate the performance of remote sensing based approach, together with its strengths and limitations compared with field experiments.

Field samples in this study were always around 10 each year. To overcome the limitation of small sample size in field surveys, 90 stratified random samples were selected with half in burned area and half in unburned area. Spectral reflectance and vegetation indices were calculated for these samples to examine the capability of Landsat imagery in revealing the vegetation's post-fire recovery.

\section{Results and Discussion}

\subsection{Visual Assessment of the Grassland Recovery}

Notice the image in May shows the defined boundary of the burn patch, especially the almost linear shape at the bottom stretching from northwest to southeast. The linear feature was primarily caused by the strong westerly wind blowing at around $40 \mathrm{~km} / \mathrm{h}$. However, the linear feature was not prominent any more one month later (June), barely visible two months later (July), and not traceable at all three months later (August). The grassland becomes homogeneous to the naked eye after three months, indicated in September's and October's images. The burn patch faded quickly and completely due to vegetation's rapid recovery.

Visual assessment of the burning suggests a quick post-fire regrowth of grasslands. There is no apparent visual difference between burned and unburned communities two months after the fire. GNP promptly assessed the fire's impact and actively monitored the effect of burning throughout the park. They photographed several locations the following day after the fire and revisited two and half months later [60] to get before- and after-burn photographs for visual pairwise comparison. Their data included the Two Trees Area that is only three kilometres east of the ignition location (Figure 1). The boundary of the burn patch at the Two Trees Area was quite prominent during their first visit. However, the well-defined boundary was lost completely to the healthy green vegetation two months later, indicating vegetation's rapid recovery at the ground level.

Meanwhile, the quick recovery was captured by the Landsat satellite. Figure 5 shows a time series of standard false-colour composite from the Landsat 8 OLI imagery. The burned patch was barely visible two months later and completely disappeared three months later. However, rare traces of the fire can still be found at the ground level. In fact, during the field trip in 2017 we observed a few charred shrubs at their roots located along the Frenchman River valley, bearing the mark of the wildfire even after five growing seasons. Nevertheless, overall at the landscape level it seems the grassland has no memory of the wildfire's disturbance that occurred a few months earlier. Though effective and straightfor- 
ward, visual interpretation can be misleading and belies the fire's potential profound impact on the ecosystem at levels that human eyes fail to capture; such impact may reach far into the future of the ecosystem [61], especially in light of the five year historical fire regime. As a result, the initial investigations conducted by the park and also Lu et al. [36] need to be extended and improved with a systematic assessment of this fire's impact on the grassland ecosystem.

\subsection{Grassland Post-Fire Recovery with Field Data}

Table 3 shows the dynamics of biophysical parameters for burned and unburned samples across six years, from pre-burn growing season (2012) to the $5^{\text {th }}$ post-fire growing season (2017). Most biophysical parameters are not significantly different between treatments. Only one third of the statistics passed the significant test if weak significant results $(\mathrm{p}=0.1)$ are also included. Although some of the weak or non-significant results can be attributed to limited sampling effort (small sample size), as well as biotic and abiotic factors other than burning, fire still demonstrated significant correlation with certain biophysical parameters and suggested fire as an important factor in shaping the grassland dynamics.

Table 3. Biophysical characteristics in burned ("B") and unburned (" $U$ ") treatments. Values show averages of biophysical parameters. Significance tests are performed to compare statistics across treatments. Results for 2012 is included as the baseline for subsequent five post-fire growing seasons. Notice some parameters were not collected consistently throughout the study period.

\begin{tabular}{|c|c|c|c|c|c|c|c|c|c|c|c|c|}
\hline \multirow{2}{*}{$\begin{array}{l}\text { Biophysical } \\
\text { Parameters }\end{array}$} & \multicolumn{2}{|c|}{2012} & \multicolumn{2}{|c|}{2013} & \multicolumn{2}{|c|}{2014} & \multicolumn{2}{|c|}{2015} & \multicolumn{2}{|c|}{2016} & \multicolumn{2}{|c|}{2017} \\
\hline & $\mathrm{U}$ & B & $\mathrm{U}$ & B & $\mathrm{U}$ & B & $\mathrm{U}$ & B & $\mathrm{U}$ & B & $\mathrm{U}$ & B \\
\hline Green (\%) & 16.7 & 22.7 & 24.4 & $45.8^{*}$ & 32.9 & 31.2 & 20.6 & 22.4 & 32.0 & 36.3 & 16.3 & 14.1 \\
\hline Forb (\%) & 7.1 & 3.9. & 6.8 & 13.0 & 6.1 & 11.6 & 4.3 & 5.6 & 3.8 & 3.7 & 4.7 & 7.3 \\
\hline Shrub (\%) & 0.7 & $2.6^{*}$ & 1.3 & 0.2 & 2.3 & 3.9 & 2.0 & $5.3^{*}$ & 7.0 & 5.8 & 1.9 & 3.0 \\
\hline Live (\%) & 24.5 & 29.2 & 32.5 & $59.0^{* *}$ & 41.3 & 46.7 & 26.9 & $37.2^{*}$ & 42.8 & 45.8 & 22.8 & 24.4 \\
\hline $\begin{array}{c}\text { Canopy Height } \\
(\mathrm{cm})\end{array}$ & - & - & - & - & 25.2 & $37.1^{*}$ & 27.4 & $37.1^{*}$ & 27.1 & 42.2 & 22.0 & 22.6 \\
\hline Stand dead (\%) & 52.1 & 49.8 & 25.6 & $0.1^{\star *}$ & 17.0 & 17.3 & 12.9 & 8.2 & 21.8 & 13.9 & 14.8 & 17.8 \\
\hline Litter (\%) & 11.4 & 12.2 & 21.8 & 14.6 & 23.1 & 14.2 & 43.7 & 43.2 & 21.5 & 36.1 . & 61.9 & 55.5 \\
\hline Dead (\%) & 63.5 & 62.0 & 47.3 & $14.7^{\star *}$ & 40.1 & 31.5 & 56.6 & 51.4 & 43.3 & 50.0 & 76.7 & 73.3 \\
\hline Lichen (\%) & 3.0 & 3.2 & 0.3 & 0.0 & 0.4 & 0.1 & 5.7 & $1.4^{*}$ & 1.8 & 0.9 & 0.1 & 0.0 \\
\hline Moss (\%) & 7.4 & $1.0^{*}$ & 13.1 & 9.2 & 10.9 & $4.4^{*}$ & 0.1 & 0.0 & 10.5 & $0.2^{*}$ & 0.0 & 0.0 \\
\hline Bare soil (\%) & 1.6 & 2.8 & 3.3 & 16.1 . & 0.9 & $9.2^{\star}$ & 8.9 & 2.6 & 1.4 & 2.5 & 0.2 & 1.5 \\
\hline LAI & 1.7 & 2.3 & 0.4 & 0.3 & 1.6 & 2.3 & 1.2 & $2.0^{*}$ & 1.2 & $2.0^{*}$ & 1.3 & 1.5 \\
\hline $\begin{array}{l}\text { Soil moisture } \\
\left(\mathrm{m}^{3} / \mathrm{m}^{3}\right)\end{array}$ & 0.2 & 0.2 & 0.2 & 0.3 & 0.2 & 0.2 & 0.1 & 0.1 & 0.1 & $0.2^{\star *}$ & 0.1 & 0.1 . \\
\hline Soil temp $\left({ }^{\circ} \mathrm{C}\right)$ & 23.3 & 25.4 & 23.4 & 22.8 & 23.2 & 21.9 & 31.2 & 32.6 & 25.8 & 24.1 & 30.3 & 30.7 \\
\hline Soil EC (dS/m) & 0.1 & $0.2^{\star *}$ & 0.1 & 0.3 & 0.1 & 0.2 & 0.0 & 0.0 & 0.0 & $0.1^{\star *}$ & 0.0 & 0.0 \\
\hline
\end{tabular}

Significant codes: “**” 0.01, , ” 0.05, “.” 0.1 . 


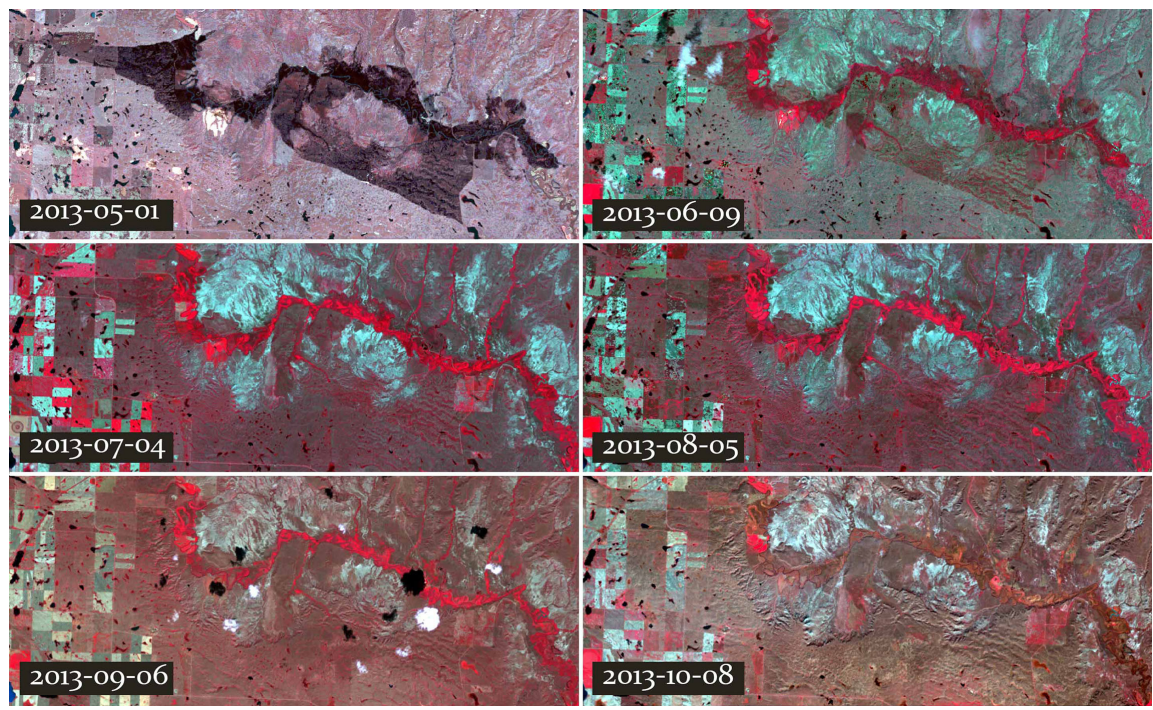

Figure 5. Visual assessment of the wildfire and vegetation's rapid regrowth. This series of six standard false-colour composite images (NIR, Red, Green) are prepared from Landsat 8 OLI sensors. They represent the fast process of grassland recovery on the monthly basis from immediately after the fire till five months afterwards.

Results show few significant differences for green grass, forb, and shrub across treatments. This might be caused by limited sample sizes available to this study. Additional analysis proves that when the three components are combined altogether as the live vegetation, a significant result was achieved. Table 3 indicates these derived parameters relatively outperform original parameters. To understand the post-fire recovery dynamics at a higher level, a ternary plot (Figure 6) was generated based in Table 3. Here "live" and "dead" components are the derived biophysical parameters discussed previously. Other parameters are summarized as the "rest" component. Such aggregation procedure allows us to trace the configurational dynamics of the three major components throughout five post-fire growing seasons. As a result, a higher level of understanding grassland post-fire recovery can be achieved.

Figure 6 has three axes ("Dead", "Live" and "Rest") defined by the three-high level components. The three axes are arranged from head to toe to form a triangular coordinate system. This technique is often used to visualize the relationships between components in a three-component mixture where components are restricted by each other in that their sum is a predefined fixed number. All data points are plotted according to their 3-tuples in the form of (dead, live, rest). Notice years are colour-coded and lines are drawn to connect burned and unburned treatments within each year. Length of the line indicates the extent of difference across treatments' three component configuration (or cross-sample configurational difference). That is, the longer the line is, the more configurational differences there are between burned and unburned samples of that year.

There exists a clear trend in the cross-sample configurational difference in time. One year prior to the fire (2012) saw little difference between samples. The 


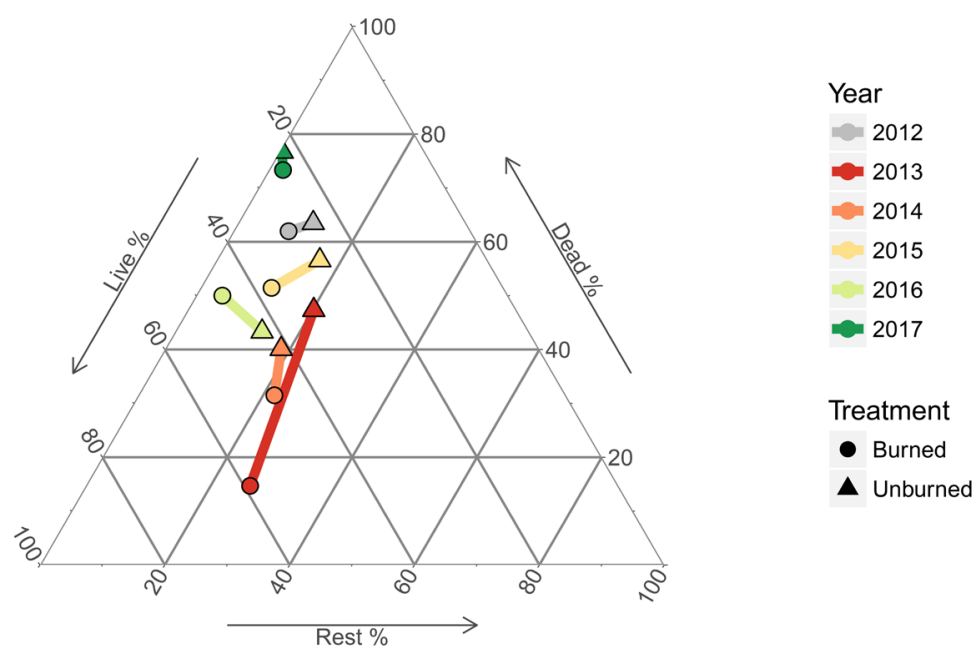

Figure 6. Overview of post-fire dynamics with higher level components in the pre- and post-fire grassland ecosystem (2012-2017). "Live" and "dead" components are derived biophysical parameters from the original measurement. Other parameters are summarized as "Rest". The figure clearly illustrates the dynamics of cross-sample configurational difference of these three components throughout five post-fire growing seasons. Field data from year 2012 is also added as the baseline (one growing season before the wildfire).

wildfire in the following year (2013) caused sudden and largest difference found in the entire time frame of this study. Afterwards, the difference gets less pronounced until it is almost non-existent across samples in the $5^{\text {th }}$ growing season (2017). The progression of vegetation's post-fire recovery suggests a full recovery of 4 - 5 years. This agrees with some research conducted in the same region. It may also reflect the historic fire regime (interval) under which the prairie adapted through long-term evolution.

The wildfire may have caused hysteresis of the ecosystem. Some ecologists believe that multiple alternative stable states exist in communities with the active state triggered by addition or exclusion of certain interactors or disturbances. More discussion about alternative stable states theory can be found in [62]. Communities can shift to alternative successional trajectories and might never return to its original community type, but might instead develop into a new community type. Hysteresis describes such behaviour as incapable of returning to the original community type, even with the original conditions fully restored back to the community.

In Figure 6, it can be noticed the overall progressively upward pattern of the post-fire recovery, with only a small setback occurring in 2015 due to water stress. But the recovery trajectory continued after 2015. Configuration in 2017 overshoots beyond that of pre-fire 2012 with significant margin, suggesting a quite different configuration or alternative state of the ecosystem. Since there were no other major disturbances present to alter the configurational structure, the hysteresis can be only explained by 2013's wildfire. However, more field dataset both in higher quality and longer time series is needed to further study this phenomenon. Meanwhile, the figure also portrays the general trend of balance 
between live and dead components of the ecosystem across time. The fire promoted the percentage of live component significantly in 2013, indicated by the burned sample positioning at the bottom of the chart (with its value at around $60 \%)$. However, the position of burned samples after 2013 have been progressively moving up in the figure (along the negative direction of the live-axis), showing a steadily decreasing trend. Meanwhile, the dead component displayed the exact opposite increasing trend accordingly. These trends indicate the effective removal of dead material by the fire and later the accumulation process.

Post-fire recovery of the live component. It is not surprising to observe fluctuations in biophysical parameters at unburned sites due to inter-annual variation in the precipitation pattern (Figure 7). This is more obvious for the green grass cover in 2015 and 2017 when both years saw significant decreases in green grass cover compared with their preceding years. Though green grass cover in 2016 might appear here as the anomaly, but the meteorological record (Figure 3) reveals that the relative low green grass cover in 2015 and 2017 was probably due to both below-normal precipitation and high moisture deficit during the growing seasons. In fact, results show that same-month precipitation explains $68 \%$ variation in green grass cover and $72 \%$ variation in the dead component cover. Though both tests were passed at a weak significance level $(\mathrm{p}=0.1)$. However, if the well-documented time lag [63] [64] [65] is considered between grassland phenology and climate variables, the statistics would be stronger and more significant.

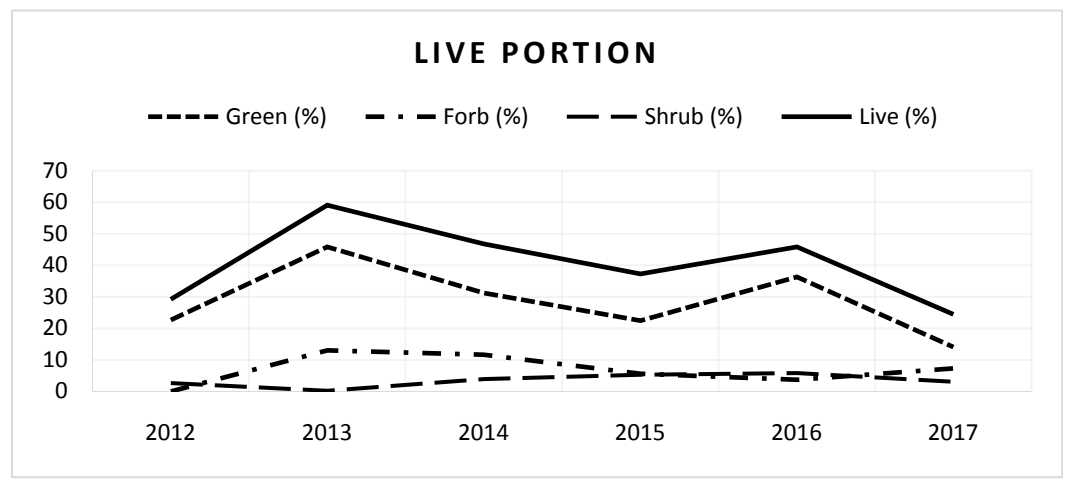

(a)

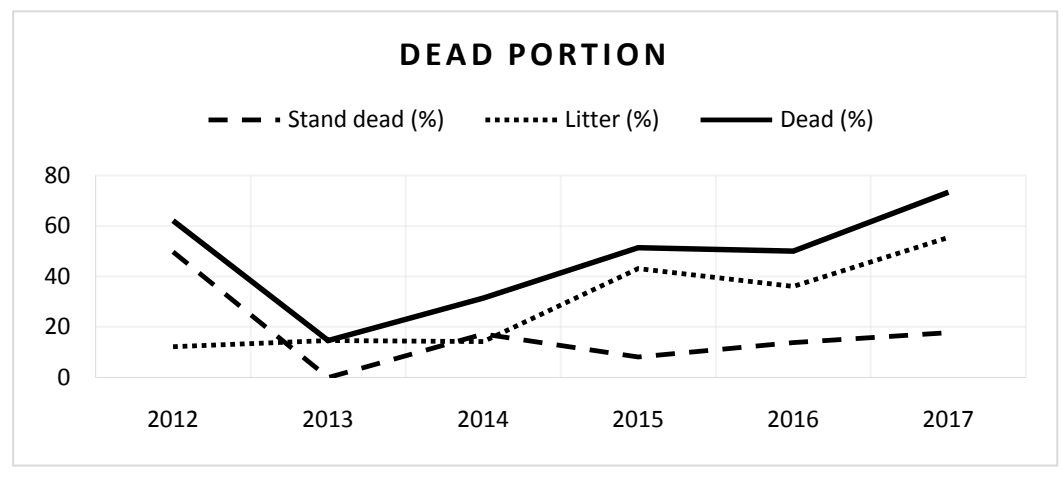

(b) 


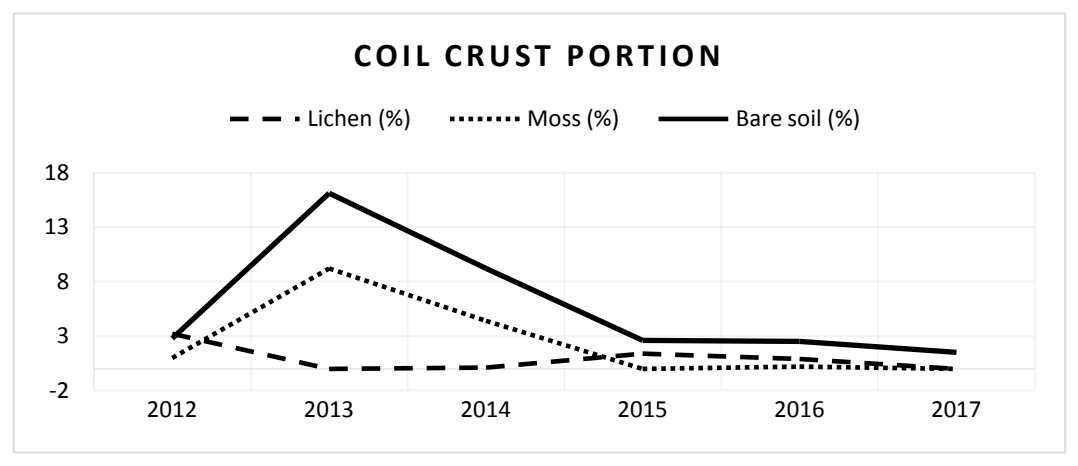

(c)

Figure 7. Vegetation recovery trajectory for different portions, (a) live portion, (b) dead portion, and (c) soil crust portion.

There was abundant precipitation following the fire, making green grass cover at both burned and unburned sites experience a large amount of growth. GNP reported that the "above normal precipitation (in May and June) resulted in a rapid re-growth of vegetation, giving the Park a lush green look" [60]. The live vegetation cover increased by as much as $82 \%$ in merely two months after the wildfire. Statistics also show a significant increase of live vegetation at burned sites into the third growing season, howbeit at a lower extent (but still 65\% higher than that of the unburned). This suggests that the dead material began to accumulate quickly at the burned sites, resulting in the less pronounced difference in the live vegetation component between burned and unburned sites in the third year. This finding may seem to agree with research on the tallgrass prairie where fire substantially increases herbaceous production due to a modified pattern of soil nitrogen as well as improved light availability [66] [67]. However, it contradicts the finding by [17] on the semi-arid shortgrass on the North American Great Plains (about $1000 \mathrm{~km}$ south of the study area in northeastern Colorado). Their prescribed fire showed no influence in herbaceous plant production in both the first and second post-fire growing seasons. This discrepancy may be caused by differences in vegetation types and various grazing pressures in these two ecosystems.

Results consistently show that burned sites have a significant $20 \%$ more green grass cover, demonstrating fire's positive impact in promoting grassland health Meanwhile, it describes the evolutionary adaptation of the prairie grass communities to disturbances like fire. Fire consumed all the standing dead and other components, broke down biomass into nutrients and opened up space for green grass to colonize on burned sites. This can be clearly confirmed from the dynamics of exposed bare soil, which was significantly higher at burned sites in the first two growing seasons. Overall it took merely one growing season for the green grass cover to restore to the unburned status. However, canopy height at burned sites is consistently more than $10 \%$ higher even at the fifth growing season (Table 3).

Fire overrides climate as the most significant force in shaping the vegetation 
community. Notice that in the second growing season due to above-normal precipitation the unburned sites experienced fast increase in green grass composition and decrease in the standing dead composition. However, the opposite scenario happened at burned sites, with the green grass composition decreased by $15 \%$ and the standing dead increased by the same amount.

Figure 7(a) shows that fire increased forb's composition in the following two growing seasons. There was a high peak of increase in forb's composition at the first growing season, coinciding with the high increase in green composition. This is obviously due to fire removing most dead component and allowing green vegetation to colonize the disturbed area. In the subsequent growing season, we observe forb's cover tends to be higher at burned sites. At the third growing season, there is no difference between treatments. Therefore, it took two growing seasons for forbs to converge to the unburned level, contrasting with grass' one-year recovery. As for the shrub, it underwent a longer recovery process simply due to severe loss of biomass from the burning. Please note that the shrub composition at the would-be-burned sites was a little higher than the unburned sites in 2012. That is expected because the fire propagated mostly along the Frenchman River valley. As a result, some of the surveyed burned sites were located in the low-lying valley area where there was more shrub presence than sites outside the valley. In fact, shrub contributes little in our research sites, with its composition always as low as $5 \%$. Notice that at the third growing season shrub cover at burned sites was significantly higher. A few samples had exceedingly high level of shrub (cover greater than $40 \%$ ). This is also when the water stress was present, with green grass and forb having converged to the same level as unburned sites.

Post-fire dynamics of the dead components. Fire effectively removed the dead component in the immediate growing season. Individual statistics of standing dead and litter component don't produce a consistently significant result. But when combining the two components there exists significant decrease in the dead component at the burned sites. This can be confirmed from the field work and is expected from related grassland fire study in this area [35] [36]. Fire effectively removed the standing senesced grasses from the past year as well as the dead material covering the ground surface. This opened space for new vegetation to take over, with unobstructed light conditions as well as nutrients from the fire-consumed ashes. The dead component at burned sites was $30 \%$ less than at unburned sites. The standing dead, which is the most combustible material to fuel the fire, was completely removed at burned sites. In the second post-fire growing season, the total dead component at burned sites was still $10 \%$ less, though at a weak significant level $(\mathrm{p}=0.1)$. Figure $7(\mathrm{~b})$ shows obviously that standing dead at burned sites has easily built up after one growing season and reaches the same percentage as at unburned sites. Overall it took two growing seasons for the dead component to converge to the unburned sites.

Post-fire dynamics of soil crust and soil properties. Fire has a profound im- 
pact on the soil crust. Its recovery took longer than four growing seasons (Figure $7(\mathrm{c})$ ). Fire initially burned most above-ground biomass, exposing bare soil which continued remaining high for two growing seasons. This made lichen composition close to none. Although precipitation helped moss composition recover but they are still significantly lower at burned sites. The water stress in 2015 affected both burned and unburned sites. Unburned sites had the live component reduced, most moss removed, and lichen exposed. However, burned sites had significantly less lichen. Precipitation at the fourth growing season helped moss at the unburned sites to recover to its un-stressed level, but failed to do so at burned sites. This indicated that burning affected the long-term soil dynamics even into the fourth growing season. In contrast, Ford and Johnson [5] found that soil crust in burned and unburned sites were at a similar level after two years of fire events. The discrepancy between this research and their sprobably was due to three reasons. First, their research site was located in southern Great Plains at Kiowa National Grassland, New Mexico-1500 km south of GNP. The environmental variables are quite different from that of the mixed prairie, causing variations in time of recovery. Second, their grassland was classified as shortgrass steppe. The predominant cover of warm-season C4 plants has distinct biophysical properties compared $\mathrm{C} 3$ plants found in the mixed prairie at GNP. Third, during their study timeframe, several months of drought occurred followed by several months of heavy precipitation. This particular weather pattern will certainly make their findings less comparable to results identified here in this research.

In semi-arid mixed grasslands, productivity is often water limited due to its impact on biological activity within the ecosystem [37]. Acting as a protective blanket [35] [68], the dead material traps water from precipitation and also helps retain water from evaporation at the soil surface. When fire removed the dead material, soil surface at the burned sites received more solar radiation; meanwhile evaporation would also increase. Vermeire et al. [68] was able to demonstrate that for burned sites soil temperature rose by $0.5^{\circ} \mathrm{C}$ during drought and was similar during a wet growing season. A consistent increase by $1 \%$ was reported in soil moisture at burned sites. However, this study does not have a significant result to indicate such change. This may be due to a few reasons. The device used in the field data collection is known to be not sensitive enough to detect the small changes in the soil parameters. Moreover, field sites were sampled at different dates usually spanning two weeks. Weather pattern and time of day can both impact the measurement.

Fire and grasslands resilience. Results suggest that fire enhances short-term health and resilience of the grasslands. GNP received below-normal precipitation in 2015, causing water stress that impacted both burned and unburned sites of that year. Now the grassland ecosystem has undergone two years of recovery from the wildfire's disturbance in 2013. And in the third year water stress settled in, causing a minor disturbance. As a result, grasslands were experiencing a 
compound effect from both wildfire and water stress. However, results indicate that wildfire's impact was masking the effect of water stress at burned sites.

It is interesting to observe that in 2015 the live component at burned sites was significantly higher at $10 \%(\mathrm{p}=0.05)$ than at the unburned sites. The significant increase coincides with a very low percentage of exposed bare soil as well as higher shrub coverage at burned sites, whereas unburned sites saw an increase in exposed bare soil and lower live component. These opposite scenarios across treatments suggest better performance of burned sites in withstanding water stress. As a result, fire promoted grassland resilience and caused grassland ecosystems to perform better under water-stressed conditions. Though the underlying mechanism of such improvement in grasslands resilience needs to be further researched, yet it still is possible to hypothesize that fire modified the local hydrological cycle through its effect on grassland covers; moreover, it probably enhanced water utilization.

Fire's positive effect on grasslands resilience lasted no more than four years. Another water stress condition appeared in 2017 with similar below-normal precipitation. However, data analysis didn't show significant differences across treatments. This indicates that the fire's influence only lasted for four years regarding its impact on grasslands health and resilience.

\subsection{Grassland Post-Fire Recovery with Ground Remote Sensing Data}

Figure 8 shows an example of the analysis result for 2013 with the live component as the biophysical parameter. Due to the limited sampling effort in the field survey, only five burned samples were included in the analysis. The explanatory power of narrow bands (wavelength ranging from $350 \mathrm{~nm}$ to $2400 \mathrm{~nm}$ at $1 \mathrm{~nm}$ interval) is indicated as the thick black line. Three regions show strong $\mathrm{r}^{2}$ values: violet region $\left(\mathrm{r}^{2}\right.$ peaks at 0.80$)$, red region $\left(\mathrm{r}^{2}\right.$ peaks at 0.55$)$, and NIR region $\left(\mathrm{r}^{2}\right.$ peaks at 0.93$)$. However, the thin black p-value line indicates only NIR region as statistically significant $(p=0.05)$, excluding the other two windows. Notice that regressions for producing this graph were carried out using only five samples due to limited field sampling effort (five burned samples and five unburned samples). Overall, we can conclude that reflectance at NIR region $(750 \mathrm{~nm}$ to $1000 \mathrm{~nm}$ ) can explain approximately $90 \%$ of the variation of live component percentage $(p=0.05)$. It is not surprising to know that this window also happens to cover the NIR band of Landsat product, shown as light pink colour bands in the background (wide band at bottom for Landsat 7 ETM+ sensor and narrow band on top for Landsat 8 OLI sensor). The scattering of NIR radiation in green vegetation's spongy mesophyll [69] is commonly used as a robust measure of green vegetation, which in this case can also serve as an effective parameter in evaluating post-fire recovery when the live component is used as the measure of recovery.

Similar plots were prepared as in Figure 8 for all the years and other two 
fire-sensitive parameters. Results were assembled and organized together according to Landsat bands. Please note that data analysis suggested an additional two sensitive windows at SWIR region: SWIRa at $1300 \mathrm{~nm}$ and SWIRb at 1950 $\mathrm{nm}$ located at two atmospheric water absorption regions [69].

\subsection{Post-Fire Recovery with Landsat Products}

Overall, Landsat product demonstrated its effectiveness in studying grasslands post-fire recovery, with the most sensitive bands being red, NIR, and two SWIR bands. When live component (live\%) is used as the parameter of measuring vegetation recovery (top section of Table 4), the most sensitive window is $750 \mathrm{~nm}$ - $1000 \mathrm{~nm}$, which corresponds to Landsat's NIR band. The second sensitive window is $625 \mathrm{~nm}-690 \mathrm{~nm}$, overlapping with Landsat's red band. The green and blue regions also showed some explanatory power but are not consistent throughout the five-year study period. Also included in the table are weak significance tests with $\mathrm{p}=0.1$ due to the limited sample size from the field survey (indicated as $\mathrm{n}$ in the table).

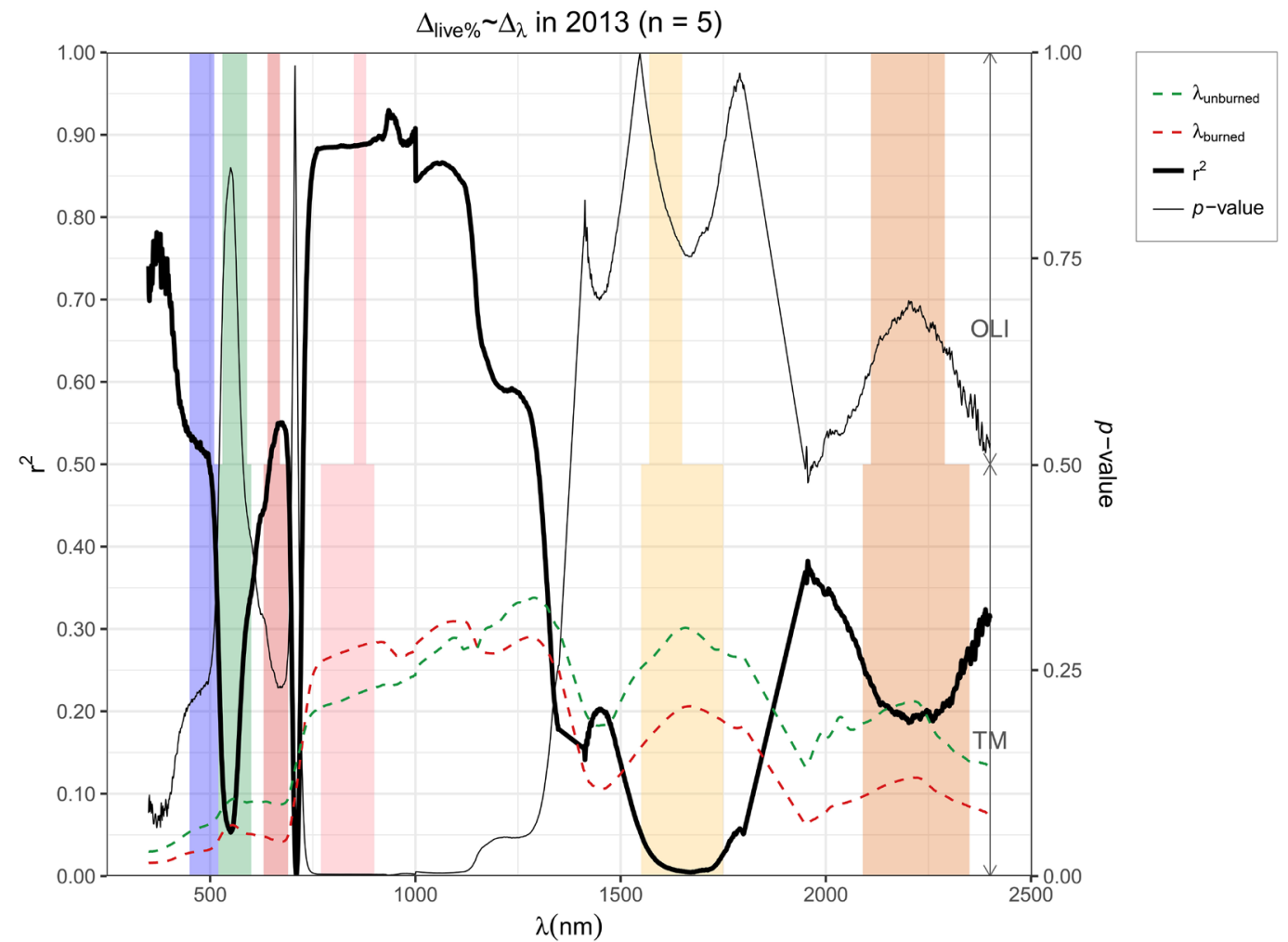

Figure 8. Power of all wavelengths in explaining the variation of fire-sensitive biophysical parameters, using the linear regression model discussed in 2.4 , with the biophysical parameter as percentage of live component (live\%) and reflectance values $(\lambda)$ measured from a spectroradiometer. The thick black line shows the $\mathrm{r}^{2}$ curve. The thin black curve indicates p-values from significance tests. Averaged reflectance curves for burned (red dashed line) and unburned (green dashed line) are superimposed as references. Color bands shown in the background are band configurations for Landsat sensors (OLI of Landsat 8 on the top; ETM+ of Landsat 7 below) plotted according to their designated wavelengths. A sensitive window from $750 \mathrm{~nm}$ to $1250 \mathrm{~nm}$ can be clearly identified from the figure. 
Table 4. Performance of satellite products at burned ("B") and unburned ("UB") sites.

\begin{tabular}{cccccccccccccc}
\hline & \multicolumn{2}{c}{2012} & \multicolumn{2}{c}{2013} & \multicolumn{2}{c}{2014} & \multicolumn{2}{c}{2015} & \multicolumn{2}{c}{2016} & \multicolumn{2}{c}{2017} \\
\cline { 2 - 13 } & $\mathrm{U}$ & $\mathrm{B}$ & $\mathrm{U}$ & $\mathrm{B}$ & $\mathrm{U}$ & $\mathrm{B}$ & $\mathrm{U}$ & $\mathrm{B}$ & $\mathrm{U}$ & $\mathrm{B}$ & $\mathrm{U}$ & $\mathrm{B}$ \\
\hline Blue (\%) & 5.2 & 5.6 & 5.3 & $3.4^{*}$ & 5.7 & $5.2^{*}$ & 7.2 & $5.6^{* * *}$ & 7.4 & $6.4^{*}$ & 5.6 & 5 \\
Green (\%) & 7.3 & 7.5 & 8.2 & $6.2^{* *}$ & 8.5 & 7.9 & 10 & $8.5^{* *}$ & 5.7 & $4.6^{* *}$ & 8.3 & 7.6 \\
Red (\%) & 7.6 & 7.8 & 8.4 & $5.2^{*}$ & 9.1 & $8.2^{*}$ & 11.3 & $8.5^{* * *}$ & 6.2 & 4.7 & 9.2 & 8.4 \\
NIR (\%) & 23.1 & 21 & 22.6 & 28.1 & 22.3 & 22.7 & 23 & $27.1^{*}$ & 21.2 & 21.2 & 22.7 & 20.9 \\
SSWIR (\%) & 25.1 & 24.9 & 27.3 & $20.5^{* *}$ & 27 & $23.5^{* * *}$ & 30.8 & $25.8^{* * *}$ & 25.4 & $21.5^{* *}$ & 27.8 & 24 \\
LSWIR (\%) & 13.4 & 14.8 & 16.9 & $12.7^{*}$ & 17 & $14.9^{* *}$ & 20.3 & $15.2^{* * *}$ & 15.2 & 12.5 & 16.9 & 14.6 \\
NDVI & 0.5 & 0.5 & 0.5 & $0.7^{*}$ & 0.4 & 0.5 & 0.3 & $0.5^{* *}$ & 0.5 & 0.6 & 0.4 & 0.4 \\
NBR & 0.2 & 0.2 & 0.1 & $0.4 \cdot$ & 0.1 & 0.2 & 0.1 & $0.3^{* * *}$ & 0.2 & 0.2 & 0.1 & 0.2 \\
EVI & 1 & 1 & 1.1 & $0.8^{*}$ & 1.4 & 1.1. & 0.7 & 1.6 & 1.3 & $0.9^{* * *}$ & 1.4 & 1 \\
SAVI & 0.3 & 0.2 & 0.3 & 0.4 & 0.2 & 0.3 & 0.2 & $0.3^{* *}$ & 0.3 & 0.3 & 0.2 & 0.2 \\
MSAVI & 0.3 & 0.2 & 0.2 & 0.4 & 0.2 & 0.2 & 0.2 & $0.3^{* *}$ & 0.3 & 0.3 & 0.2 & 0.2 \\
BAI & 3.1 & 3.3 & 3.1 & 2.9 & 3.1 & 3.2 & 3 & 2.8 & 3.4 & 3.5 & 3.1 & 3.3 \\
CSI & 1.7 & 1.4 & 1.3 & $2.4^{* *}$ & 1.3 & 1.5 & 1.2 & $1.9^{*}$ & 1.4 & 1.8 & 1.3 & 1.5 \\
MIRBI & 0.9 & 1 & 1 & $1.3^{*}$ & 1.1 & $1.2^{*}$ & 1 & 1 & 1 & 1.1 & 1 & 1.1 \\
GEMI & 0.6 & 0.5 & 0.5 & 0.7 & 0.5 & 0.5 & 0.5 & $0.6^{* *}$ & 0.5 & 0.6 & 0.5 & 0.5 \\
\hline
\end{tabular}

Significant codes: “***” 0.001 , “**” 0.01 , “*” 0.05, “.” 0.1 .

Performance of individual bands. Spectral reflectance from satellite imagery demonstrated significant power in distinguishing different treatments for five consecutive seasons. Across five post-fire growing seasons, spectral reflectance of all Landsat bands were significantly lower at burned sites than the unburned, except near the infrared band (NIR) which saw higher reflectance in burned sites howbeit most results were not statistically significant. Moreover, for the aforementioned non-NIR bands, the difference of spectral reflectance between treatments generally displayed a decreasing trend. This implies that fire's impact is fading in the process of vegetation recovery, with burned sites converging to the unburned, making both treatments appear homogeneous. For the fourth season some statistics became weaker (Red, SWIR2) and eventually in the fifth season all statistics were non-significant, implying the fact that the burned communities had almost fully recovered.

Notice the anomalies which occurred following 2015 where the converging trend was disturbed. This is caused by the water stress in 2015, which affected the post-fire recovery. However, the converging trend continued consistently after 2015. Some claim fire as a "global herbivore" [2]. Here the statistics suggest that drought can also mimic fire's impact. At a glance, it can be regarded as a minor "fire". It decreased the reflectance signature of both treatments, proving itself as a "global herbivore". However, we observe more pronounced contrast between treatments, with burned sites still have much higher reflectance as in 
previous growing seasons, suggesting fire's profound impact. More research is needed to quantify the impact of drought, fire and herbivores, the three most common and interconnected disturbances in shaping the grasslands.

Responses from the three visible bands (especially the red band) are significantly smaller at burned sites than the unburned. This is because burned sites tend to have more live component (green vegetation) and less dead material (standing dead and litter). Chlorophyll and other pigments in healthy green vegetation absorbing red spectrum for photosynthesis, making reflectance in that region significantly lower than the unburned sites that have less live component. On the other hand, the light-coloured standing dead and other non-photosynthetic vegetation (NPV) have higher reflectance at visible bands and appear brighter. However, across time the difference of reflectance in visible bands between treatments became less pronounced, from $3.2 \%$ in 2013 to $0.8 \%$ in 2017. As the grasslands recovered, burned sites started to build up the dead material and the contrast in the visible bands was getting less obvious.

SWIR1 and SWIR2 are vivo water content related [70] with healthy vegetation exhibiting more absorption than otherwise. Similar results were shown as three visible bands, emphasizing the extra live component during vegetation's recovery from the burning, and both bands experienced similar converging trend between treatments.

NIR is the only band which showed increased reflectance at burned sites, simply because of the more healthy live component at burned sites. Though we expect to see a consistent and significantly higher reflectance in NIR at burned sites, satellite data suggested otherwise. Yang et al. [35] investigated fire's effect in the same study area and also reported that NIR increase at some burned sites showed no statistical significance. Across five post-fire growing seasons, only 2015 saw a significant increase in NIR by $4 \%$ at burned sites. The insignificant result for other growing seasons may be due to limited sample size, and large variations in the live component at the burned sites.

In SWIR2 region, solar radiation can be significantly absorbed by the water content in green vegetation or soils. Meanwhile, research [71] [72] also suggests that dry soil exposure after burning would increase SWIR2 reflection. Water absorption in SWIR1 is considerably weaker. However, this study showed the opposite relationship. There was significant decrease in both SWIR bands at burned sites. This can be explained by the increased composition in green vegetation for the burned sites which had higher water content than unburned sites. As a result, SWIR regions in burned sites had more absorption and less reflectance. Although for unburned sites the significant amount of dead material helped to retain water. However, in this study we don't see this effect from SWIR bands. This is probably because SWIR bands couldn't penetrate the vegetation structure and pick up the water's signal in the dead material at the soil surface. Furthermore, Landsat 8 imagery acquired five days after the burn also indicated lower SWIR responses for burned sites. This is probably due to the presence of charred soils found at the burned sites which had lower reflectance in both 
SWIR regions than unburned sites where senescent grasses were dominant [36]. Overall, we observe lower reflectance in SWIR region for burned sites from right after the burn, till the third year. This finding contradicts [72], probably due to the difference in ecosystems and vegetation types.

Performance of Vis. Although individual spectral bands demonstrated promising capability in separating treatments, commonly used broadband vegetation and fire indices showed mixed results with most statistics non-significant, demonstrating the pressing and challenging issue of finding a suitable vegetation index in monitoring vegetation recovery from the fire. Detailed results can be summarized in Table 4.

The algorithm of NDVI involves NIR and red bands, and has been widely used in the literature as an important index for studying green vegetation as well as fires. In this study, although NIR band didn't have a good performance from the statistical perspective, we did find a good performance from NDVI. We saw a significant increase in NDVI for the burned sites in the first (by 44\%) and third growing season (by 49\%). NDVI for burned sites in the second and fourth growing season also increased but was not statistically significant.

NBR is a widely-used fire index expressed as the normalized difference between NIR and LSWIR. It can distinguish green vegetation from soil based on their contrasting reflectance signatures at these two bands. This study confirms its performance in such ability. NBR at burned sites was as much as 1.5 to 4 times higher than that at unburned sites. Though its performance varied from weak in the first year to not significant in the second year, and became strong in the third year. This result proves NBR as a reliable long-term fire index suitable for studying grassland fires.

EVI is another commonly used vegetation index which was developed to overcome the limitation of NDVI. However, this study demonstrates that EVI's performance is not as good as NDVI in studying fires at GNP, even though burned sites had significant lower reflectance in blue band. Instead of increasing as we see in NDVI, EVI in this case is lower in burned communities. Its weak performance may be affected by high percentage of dead material dominant in GNP grasslands.

Both SAVI and MSAVI were developed as a modification of NDVI to correct the influence of soil brightness in ecosystems with low vegetation cover and exposed soil surface. However, this study found that both didn't perform well in terms of distinguishing burned and unburned grass communities. We see these indices are greater at burned sites. From a theoretic perspective, they should have good performance for the first two years because percentage of bare soil exposure is relatively high at burned sites. However, it is interesting to find both indices can only distinguish burned sites in the third year with statistical significance. This is also when bare soil percentage was lowest in burned sites. The poor performance may due to a few reasons. The soil brightness correction factor (parameter L) for calculating SAVI may need fine-tuning in this study. 
Meanwhile, these indices are developed to overcome the influence of soils at the cost of being less sensitive to vegetation changes that are essential in studying post-fire vegetation recovery.

The Burned Area Index (BAI) and Char Soil Index (CSI) were designed to detect the char signal [73]. However, this study finds that they are not suitable for grasslands fire study in GNP. Possibly because grassland ecosystems have a higher turnover rate and grass communities are well adapted to disturbances like fire. As a result, their fast recovery will block the char signal from being captured by remote sensors. Mid-Infrared Burn Index (MIRBI) was a fire index developed for the savannah ecosystem, where NIR is less useful because of senescent vegetation in the fire season. Literature shows MIRBI to be relatively stable in performance over time. MIRBI also performed well in this study, showing significantly greater values in the burned sites than the unburned, though not significant in the third year.

\subsection{Vegetation Recovery Trajectory from Landsat NDVI}

Removing the limitation of sample size, with only satellite imagery data, the difference between burned and unburned sites is shown clearly for within years and an overall decreasing trend from 2013 to 2016, reflecting the climate variation of the same period. Though 2017 is also an extremely dry year in this area, the impact of drought didn't settle in till late July (Figure 9) which is outside the analyzed time frame. Grasslands recovery is closely tied to climatic variables. Though both burned and unburned grassland underwent a similar recovery scenario, yet they carry significant differences. Burned grassland always maintained higher NDVI values compared with its unburned counterpart, which can be explained by the fire's positive impact on the ecosystem. When peak NDVI values (corresponding to the maximum growing season) are considered, we observe such positive influence gradually dying out across time, from $30 \%$ higher in 2013 to 10\% higher in 2014 and eventually almost non-existent in 2016. This result may suggest a fire regime with a period of four years to be ideal for the prairie ecosystem. But fire's impact is more profound when we look at the start of the growing season, burned communities consistently exhibit higher NDVI values. This either means the burned site has an earlier start to the growing season, or the burned site always tends to grow greener vegetation. Since there is no apparent phase shift (a.k.a. time delay in the signal) between the two curves, the former hypothesis may not seem to be a plausible explanation. However, [74] [75] indeed reported the greenup being advanced by one week or as much as one month at burned sites due to relatively warmer soil temperatures during the day. Therefore to clarify this, better satellite remote sensing datasets need to be analyzed, especially with fine-tuned temporal resolution during the greenup period for the study area. Nonetheless, we can certainly observe the impact of grassland fire even at the fifth growing season, with both climate variation (2013-2017) and a minor disturbance (water-stress condition in 2015) considered. 


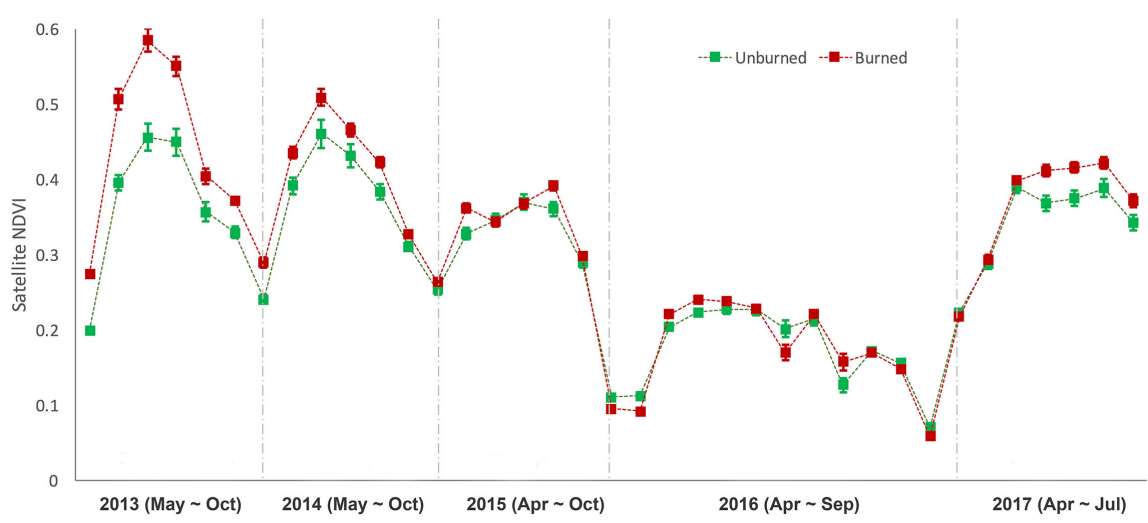

Figure 9. Satellite NDVI demonstrates the effectiveness of NDVI as a post-fire recovery indicator (error bar indicates one standard error). Notice there are more scenes available for year 2016.

\section{Conclusion}

This study found that vegetation could recover quickly from the spring burning. Starting from the first post-fire growing season, the grasslands ecosystem has begun the quick process of regeneration, and even resulted in establishment on previously bare soil. This demonstrates the strong resilience of the mixed prairie due to its adaption to frequent grassland fires in the past. Fire effectively removed the dominant dead component in the ecosystem and promoted the regeneration of the grasslands, indicated by the increased green live component in the burned communities. However, the difference between burned and unburned communities get less pronounced across time as vegetation recovers. In the third post-fire growing season, the burned communities started to converge back to the physiology of the unburned communities. Results suggested that remote sensing product is effective in detecting post-fire vegetation recovery. Some vegetation indices are sensitive in such detection. NDVI as a widely used vegetation index is a good indicator, suggesting the possibility of studying fire ecology in an even longer time frame in light of the rich and cost-effective remote sensing data archive available. Overall, Landsat product demonstrated its effectiveness in studying grasslands post-fire recovery, with the most sensitive bands being NIR, red, and two SWIR bands. Landsat NIR and red bands are the primary and secondary strong predictors of variation in the live component if green vegetation is the main focus of vegetation post-fire recovery. When the dead component is also considered as part of vegetation recovery, Landsat SWIR bands can be used as they correlate well with SRIbio and NDIbio. Two other SWIR bands sometimes demonstrated stronger relationship than the current Landsat SWIR bands. But overall sensitive wavelength windows for SRIbio and NDIbio are less concentrated than that of the live component, indicating the challenge of developing the best remote sensing index for quantifying live-dead dynamics of grasslands post-fire recovery. $\mathrm{Li}$ and Guo [76] have reviewed the remote sensing approaches in quantifying non-photosynthetic vegetation (dead materials). They mentioned the claim from related researchers [77] [78] on the 
feasibility of detecting NPV based on wavelengths from $400 \mathrm{~nm}$ to $2500 \mathrm{~nm}$. However, in reality NPV estimation is always complicated due to the presence of water, soil mineralogy, and soil organic carbon [76] [79] [80]. This is especially the case in the mixed-prairie [76].

\section{Acknowledgements}

This research was supported by Natural Sciences and Engineering Research Council of Canada (NSERC). Authors would like to thank the logistic support from Grasslands National Park of Canada.

\section{Conflicts of Interest}

The authors declare no conflicts of interest regarding the publication of this paper.

\section{References}

[1] White, P.S. (1979) Pattern, Process, and Natural Disturbance in Vegetation. The Botanical Review, 45, 229-299. https://doi.org/10.1007/BF02860857

[2] Bond, W.J. and Keeley, J.E. (2005) Fire as a Global "Herbivore": The Ecology and Evolution of Flammable Ecosystems. Trends in Ecology \& Evolution, 20, 387-394. https://doi.org/10.1016/j.tree.2005.04.025

[3] Grover, H.D. and Musick, H.B. (1990) Shrubland Encroachment in Southern New Mexico, U.S.A.: An Analysis of Desertification Processes in the American Southwest. Climatic Change, 17, 305-330. https://doi.org/10.1007/BF00138373

[4] Wright, H.A. and Bailey, A.W. (1982) Fire Ecology-United States and Southern Canada. John Wiley and Sons, New York.

[5] Ford, P.L. and Johnson, G.V. (2006) Effects of Dormant- vs. Growing-Season Fire in Shortgrass Steppe: Biological Soil Crust and Perennial Grass Responses. Journal of Arid Environments, 67, 1-14.https://doi.org/10.1016/j.jaridenv.2006.01.020

[6] Ford, P.L. and McPherson, G.R. (1996) Ecology of Fire in Shortgrass Prairie of the Southern Great Plains. Ecosystem Disturbance \& Wildlife Conservation in Western Grasslands: A Symposium Proceedings, 20-39.

[7] Dwyer, D.D. and Pieper, R.D. (1967) Fire Effects of Blue Grama-Pinyon-Juniper Rangeland in New Mexico. Journal of Range Management, 20, 359-362. https://doi.org/10.2307/3896405

[8] Launchbaugh, J.L. (1964) Effects of Early Spring Burning on Yields of Native Vegetation. Journal of Range Management, 17, 5-6. https://doi.org/10.2307/3895539

[9] Steuter, A.A. and McPherson, G.R. (1995) Fire as a Physical Stress. In: Bedunah, D.J. and Sosebee, R.E., Eds., Wildland Plants. Physiological Ecology and Developmental Morphology, Society for Range Management, Denver, CO, 550-579.

[10] Rannie, W.F. (2001) The "Grass Fire Era" on the Southeastern Canadian Prairies. Prairie Perspectives, 4, 1-19.

[11] Wakimoto, R.H., Willard, E.E., Hedrich, M. and Reid, B. (2005) Historic Fire Regimes and Change since European Settlement on the Northern Mixed Prairie: Effect on Ecosystem Function and Fire Behavior. University of Montana, Missoula, MT.

[12] Madden, E.M., Hansen, A.J. and Murphy, R.K. (1999) Influence of Prescribed Fire History on Habitat and Abundance of Passerine Birds in Northern Mixed-Grass 
Prairie. The Canadian Field-Naturalist, 113, 627-640.

[13] Umbanhowar, C.E. (1996) Recent Fire History of the Northern Great Plains. The American Midland Naturalist, 135, 115-121. https://doi.org/10.2307/2426877

[14] Redmann, R. (1978) Plant and Soil Water Potentials Following Fire in a Northern Mixed Grassland. Journal of Range Management, 31, 443-445. https://doi.org/10.2307/3897203

[15] Kruger, S. (2001) Effects of Fire on Range Plant Species in the Northern Mixed Grass Prairie. The University of Montana, Missoula.

[16] Anderson, K.L., Smith, E.F. and Owensby, C.E. (1970) Burning Bluestem Range. Journal of Range Management, 23, 81-92. https://doi.org/10.2307/3896105

[17] Augustine, D.J., Derner, J.D. and Milchunas, D.G. (2010) Prescribed Fire, Grazing, and Herbaceous Plant Production in Shortgrass Steppe. Rangeland Ecology \& Management, 63, 317-323. https://doi.org/10.2111/REM-D-09-00044.1

[18] Collins, S.L. and Wallace, L.L. (1990) Fire in North American Tallgrass Prairies. University of Oklahoma Press, Norman.

[19] Knapp, E.E., Estes, B.L. and Skinner, C.N. (2009) Ecological Effects of Prescribed Fire Season: A Literature Review and Synthesis for Managers. Albany. https://doi.org/10.2737/PSW-GTR-224

[20] Kucera, C.L. (1981) Grasslands and Fire. In: Fire Regimes and Ecosystem Properties, USDA Forest Service, Honolulu, 90-111.

[21] La Pierre, K.J., et al. (2011) Explaining Temporal Variation in Above-Ground Productivity in a Mesic Grassland: The Role of Climate and Flowering. Journal of Ecology, 99, 1250-1262. https://doi.org/10.1111/j.1365-2745.2011.01844.x

[22] Vogl, R.J. (1979) Some Basic Principles of Grassland Fire Management. Environmental Management, 3, 51-57. https://doi.org/10.1007/BF01867068

[23] Franklin, J.F., Bledsoe, C.S. and Callahan, J.T. (1990) Contributions of the Long-Term Ecological Research Program: An Expanded Network of Scientists, Sites, and Programs Can Provide Crucial Comparative Analyses. Bioscience, 40, 509-523. https://doi.org/10.2307/1311319

[24] Knapp, A.K., Fahnestock, J.T., Hamburg, S.P., Statland, L.B., Seastedt, T.R. and Schimel, D.S. (1993) Landscape Patterns in Soil-Plant Water Relations and Primary Production in Tallgrass Prairie. Ecology, 74, 549-560.

https://doi.org/10.2307/1939315

[25] Knapp, A.K., Briggs, J.M., Hartnett, D.C. and Collins, S.L. (1998) Grassland Dynamics: Long-Term Ecological Research in Tallgrass Prairie. Oxford University Press, New York.

[26] Rollins, M.G. (2009) Landfire: A Nationally Consistent Vegetation, Wildland Fire, and Fuel Assessment. International Journal of Wildland Fire, 18, 235-249. https://doi.org/10.1071/WF08088

[27] Heirman, A.L. and Wright, H.A. (1973) Fire in Medium Fuels of West Texas. Journal of Range Management, 26, 331-335. https://doi.org/10.2307/3896849

[28] White, R.S. and Currie, P.O. (1983) Prescribed Burning in the Northern Great Plains: Yield and Cover Responses of 3 Forage Species in the Mixed Grass Prairie. Journal of Range Management, 36, 179-183. https://doi.org/10.2307/3898158

[29] USDA (2018) Fire Effects Information System: Syntheses about Fire Ecology and Fire Regimes in the United States. https://www.feis-crs.org/feis/

[30] Oesterheld, M., Loreti, J., Semmartin, M. and Paruelo, J.M. (1999) Grazing, Fire, 
and Climate Effects on Primary Productivity of Grasslands and Savanna. In: Ecosystems of the World 16 Ecosystems of Disturbed Ground, Elsevier, New York, 287-306.

[31] Guo, X., Price, K.P. and Stiles, J.M. (2000) Biophysical and Spectral Characteristics of Cool- and Warm-Season Grasslands under Three Land Management Practices in Eastern Kansas. Natural Resources Research, 9, 321-331. https://doi.org/10.1023/A:1011513527965

[32] Ford, P.L. (1999) Response of Buffalograss (Buchloe dactyloides) and Blue Grama (Bouteloua gracilis) to Fire. Great Plains Research, 9, 261-276.

[33] Glitzenstein, J.S., Platt, W.J. and Streng, D.R. (1995) Effects of Fire Regime and Habitat on Tree Dynamics in North Florida Longleaf Pine Savannas. Ecological Monographs, 65, 441-476. https://doi.org/10.2307/2963498

[34] Li, M. and Guo, X. (2014) Long Term Effect of Major Disturbances on the Northern Mixed Grassland Ecosystem-A Review. Open Journal of Ecology, 4, 214-233. https://doi.org/10.4236/oje.2014.44021

[35] Yang, X., Kovach, E. and Guo, X. (2013) Biophysical and Spectral Responses to Various Burn Treatments in the Northern Mixed-Grass Prairie. Canadian Journal of Remote Sensing, 39, 175-184. https://doi.org/10.5589/m13-023

[36] Lu, B., He, Y. and Tong, A. (2016) Evaluation of Spectral Indices for Estimating Burn Severity in Semiarid Grasslands. International Journal of Wildland Fire, 25, 147-157. https://doi.org/10.1071/WF15098

[37] Schröder, B. (2006) Pattern, Process, and Function in Landscape Ecology and Catchment Hydrology-How Can Quantitative Landscape Ecology Support Predictions in Ungauged Basins? Hydrology and Earth System Sciences Discussions, 3, 1185-1214. https://doi.org/10.5194/hessd-3-1185-2006

[38] Jayaweera, K.O.L.F. and Ahlnas, K. (1974) Detection of Thunderstorms from Satellite Imagery for Forest Fire Control. Journal of Forestry, 72, 768-770.

[39] Rauste, Y., Herland, E., Frelander, H., Soini, K., Kuoremaki, T. and Ruokari, A. (1997) Satellite-Based Forest Fire Detection for Fire Control in Boreal Forests. International Journal of Remote Sensing, 18, 2641-2656. https://doi.org/10.1080/014311697217512

[40] Chuvieco, E., Ventura, G. and Martín, M.P. (2005) AVHRR Multitemporal Compositing Techniques for Burned Land Mapping. International Journal of Remote Sensing, 26, 1013-1018. https://doi.org/10.1080/01431160412331299235

[41] Petropoulos, G.P., Kontoes, C. and Keramitsoglou, I. (2011) Burnt Area Delineation from a Uni-Temporal Perspective Based on Landsat TM Imagery Classification Using Support Vector Machines. International Journal of Applied Earth Observation and Geoinformation, 13, 70-80. https://doi.org/10.1016/j.jag.2010.06.008

[42] Van Wagtendonk, J.W., Root, R.R. and Key, C.H. (2004) Comparison of AVIRIS and Landsat ETM+ Detection Capabilities for Burn Severity. Remote Sensing of Environment, 92, 397-408. https://doi.org/10.1016/j.rse.2003.12.015

[43] Dubinin, M., Potapov, P., Lushchekina, A. and Radeloff, V.C. (2010) Reconstructing Long Time Series of Burned Areas in Arid Grasslands of Southern Russia by Satellite Remote Sensing. Remote Sensing of Environment, 114, 1638-1648. https://doi.org/10.1016/j.rse.2010.02.010

[44] Anderson, R.C. (2006) Evolution and Origin of the Central Grassland of North America: Climate, Fire, and Mammalian Grazers. The Journal of the Torrey Botanical Society, 133, 626-647. 
https://doi.org/10.3159/1095-5674(2006)133[626:EAOOTC]2.0.CO;2

[45] GNP (2017) 2010 Grasslands National Park of Canada Management Plan. http://www.pc.gc.ca/eng/pn-np/sk/grasslands/plan/plan6.aspx

[46] Csillag, F., Kertész M., Davidson, A. and Mitchell, S. (2001) On the Measurement of Diversity-Productivity Relationships in a Northern Mixed Grass Prairie (Grasslands National Park, Saskatchewan, Canada). Community Ecology, 2, 145-159. https://doi.org/10.1556/ComEc.2.2001.2.2

[47] Sauer, C. (1950) Grassland Climax, Fire, and Man. Journal of Range Management, 3, 16-21. https://doi.org/10.2307/3894702

[48] Holechek, J.L., Pieper, R.D. and Herbel, C.H. (1998) Range Management: Principles and Practices. Prentice Hall, Upper Saddle River.

[49] Guo, X., Zhang, C., Wilmshurst, J. and Sissons, R. (2005) Monitoring Grassland Health with Remote Sensing Approaches. Prairie Perspectives, 8, 11-22.

[50] Parks Canada (2013) National Parks of Canada: Ecological Integrity. http://www.pc.gc.ca/progs/np-pn/ie-ei.aspx

[51] Gibson, D.J. and Hulbert, L.C. (1987) Effects of Fire, Topography and Year-to-Year Climatic Variation on Species Composition in Tallgrass Prairie. Vegetatio, 72, 175-185.

[52] Yang, X. and Guo, X. (2014) Quantifying Responses of Spectral Vegetation Indices to Dead Materials in Mixed Grasslands. Remote Sensing, 6, 4289-4304. https://doi.org/10.3390/rs6054289

[53] Albini, F.A. (1976) Estimating Wildfire Behavior and Effects.

[54] Li, Z. and Guo, X. (2018) Non-Photosynthetic Vegetation Biomass Estimation in Semiarid Canada Mixed Grasslands Using Ground Hyperspectral Data, Landsat 8 OLI, and Sentinetl-2 Images. International Journal of Remote Sensing, 39, 6893-6913. https://doi.org/10.1080/01431161.2018.1468105

[55] He, Y., Guo, X., Wilmshurst, J. and Si, B.C. (2006) Studying Mixed Grassland Ecosystems II: Optimum Pixel Size. Canadian Journal of Remote Sensing, 32, 108-115. https://doi.org/10.5589/m06-018

[56] Environment Canada (2017) Historical Data (Home > Environment and Natural Resources $>$ Weather, Climate and Hazard $>$ Past Weather and Climate). http://climate.weather.gc.ca/historical_data/search_historic_data_e.html

[57] Farmwest (2017) Evapotranspiration Dataset. http://www.farmwest.com/

[58] Barsi, J.A., Lee, K., Kvaran, G., Markham, B.L. and Pedelty, J.A. (2014) The Spectral Response of the Landsat-8 Operational Land Imager. Remote Sensing, 6, 10232-10251. https://doi.org/10.3390/rs61010232

[59] Price, K., Guo, X. and Stiles, J. (2002) Optimal Landsat TM Band Combinations and Vegetation Indices for Discrimination of Six Grassland Types in Eastern Kansas. International Journal of Remote Sensing, 23, 5031-5042. https://doi.org/10.1080/01431160210121764

[60] Parks Canada (2013) Grasslands National Park What's New. Parks Canada Homepage. http://www.pc.gc.ca/eng/pn-np/sk/grasslands/ne.aspx

[61] Pickett, S.T.A., Kolasa, J., Armesto, J.J. and Collins, S.L. (1989) The Ecological Concept of Disturbance and Its Expression at Various Hierarchical Levels. Oikos, 54, 129-136. https://doi.org/10.2307/3565258

[62] Cain, M.L., Bowman, W.D. and Hacker, S.D. (2011) Alternative Stable States. In: Ecology, Second Edition, Sinauer Associates, Inc., Sunderland, 357-362. 
[63] Guo, X. (2002) Discrimination of Saskatchewan Prairie Ecoregions Using Multitemporal 10-Day Composite NDVI Data. Prairie Perspectives: Geographical Essays, 5, 176-188.

[64] Guo, X., Wilmshurst, J., Mccanny, S., Fargey, P. and Richard, P. (2004) Measuring Spatial and Vertical Heterogeneity of Grasslands Using Remote Sensing Techniques. Journal of Environmental Informatics, 3, 24-32. https://doi.org/10.3808/jei.200400024

[65] He, Y. (2008) Modeling Grassland Productivity through Remote Sensing Products. University of Saskatchewan, Saskatoon.

[66] Blair, J.M. (1997) Fire, N Availability, and Plant Response in Grasslands: A Test of the Transient Maxima Hypothesis. Ecology, 78, 2359-2368. https://doi.org/10.1890/0012-9658(1997)078[2359:FNAAPR]2.0.CO;2

[67] Johnson, L.C. and Matchett, J.R. (2001) Fire and Grazing Regulate Belowground Processes in Tallgrass Prairie. Ecology, 82, 3377-3389. https://doi.org/10.1890/0012-9658(2001)082[3377:FAGRBP]2.0.CO;2

[68] Vermeire, L.T., Crowder, J.L. and Wester, D.B. (2011) Plant Community and Soil Environment Response to Summer Fire in the Northern Great Plains. Rangeland Ecology \& Management, 64, 37-46. https://doi.org/10.2111/REM-D-10-00049.1

[69] Jensen, J.R. (2005) Introductory Digital Image Processing: A Remote Sensing Perspective. 3rd Edition, Pearson Education, Inc., Upper Saddle River.

[70] Fourty, T. (1997) Vegetation Water and Dry Matter Contents Estimated from Top-of-the-Atmosphere Reflectance Data: A Simulation Study. Remote Sensing of Environment, 61, 34-45. https://doi.org/10.1016/S0034-4257(96)00238-6

[71] Key, C.H. and Benson, N.C. (2006) Remote Sensing Measure of Severity, the Normalized Burn Ratio. In: Lutes, D.C., Ed., FIREMON: Fire Effects Monitoring and Inventory System, Rocky Mountains Research Station, USDA Forest Service, Fort Collins, LA-26.

[72] Schepers, L., Haest, B., Veraverbeke, S., Spanhove, T., Vanden Borre, J. and Goossens, R. (2014) Burned Area Detection and Burn Severity Assessment of a Heathland Fire in Belgium Using Airborne Imaging Spectroscopy (APEX). Remote Sensing, 6, 1803-1826. https://doi.org/10.3390/rs6031803

[73] Chuvieco, E., Martín, M.P. and Palacios, A. (2002) Assessment of Different Spectral Indices in the Red-near-Infrared Spectral Domain for burned Land Discrimination. International Journal of Remote Sensing, 23, 5103-5110. https://doi.org/10.1080/01431160210153129

[74] Peet, M., Anderson, R.C. and Adams, M.S. (1975) Effect of Fire on Big Bluestem Production. The American Midland Naturalist, 94, 15-26. https://doi.org/10.2307/2424534

[75] Knapp, A.K. (1984) Post-Burn Differences in Solar Radiation, Leaf Temperature, and Water Stress Influencing Production in a Lowland Prairie. American Journal of Botany, 71, 220-227. https://doi.org/10.1002/j.1537-2197.1984.tb12507.x

[76] Li, Z. and Guo, X. (2015) Remote Sensing of Terrestrial Non-Photosynthetic Vegetation Using Hyperspectral, Multispectral, SAR, and LiDAR Data. Progress in Physical Geography, 40, 276-304. https://doi.org/10.1177/0309133315582005

[77] Gao, B.C. and Goetz, A.F.H. (1994) Extraction of Dry Leaf Spectral Features from Reflectance Spectra of Green Vegetation. Remote Sensing of Environment, 47, 369-374. https://doi.org/10.1016/0034-4257(94)90104-X

[78] Asner, G.P. (1998) Biophysical and Biochemical Sources of Variability in Canopy 
Reflectance. Remote Sensing of Environment, 64, 234-253.

https://doi.org/10.1016/S0034-4257(98)00014-5

[79] Daughtry, C.S.T., Hunt, E.R. and McMurtrey, J.E. (2004) Assessing Crop Residue Cover Using Shortwave Infrared Reflectance. Remote Sensing of Environment, 90, 126-134. https://doi.org/10.1016/j.rse.2003.10.023

[80] Cao, J.C., Matsushita, B. and Imura, H. (2010) Developing a MODIS-Based Index to Discriminate Dead Fuel from Photosynthetic Vegetation and Soil Background in the Asian Steppe Area. International Journal of Remote Sensing, 31, 1589-1604. https://doi.org/10.1080/01431160903475274 